\title{
Ocean acidification induces distinct metabolic responses in subtropical zooplankton under oligotrophic conditions and after simulated upwelling
}

\section{Natalia Osma ${ }^{\mathrm{a}, \mathrm{b}, *}$, Cristian A. Vargas ${ }^{\mathrm{a}, \mathrm{b}, \mathrm{c}}$, María Algueró-Muñíz ${ }^{\mathrm{d}}$, Lennart T. Bach ${ }^{\mathrm{e}}$, May Gómez ${ }^{\mathrm{f}}$, Henriette G. Horn ${ }^{\mathrm{g}}$, Andrea Ludwig ${ }^{\mathrm{h}}$, Theodore T. Packard ${ }^{\mathrm{f}}$, Ulf Riebesell ${ }^{\mathrm{h}}$, Vanesa Romero-Kutzner ${ }^{\mathrm{f}}$, Jan Taucher $^{\mathrm{h}}$, Igor Fernández-Urruzola ${ }^{\mathrm{a}, * *}$}

\footnotetext{
${ }^{a}$ Millennium Institute of Oceanography (IMO), Universidad de Concepción, Concepción, Chile

${ }^{\mathrm{b}}$ Department of Aquatic Systems, Faculty of Environmental Science, Universidad de Concepción, Concepción, Chile

c Coastal Socio-Ecological Millennium Institute (SECOS), Universidad de Concepción, Concepción, Chile

${ }^{\mathrm{d}}$ Institute of Biodiversity, Animal Health \& Comparative Medicine, University of Glasgow, Glasgow, UK

e Institute for Marine and Antarctic Studies, University of Tasmania, Tasmania, Australia

${ }^{\mathrm{f}}$ Marine Ecophysiology Group (EOMAR), IU-ECOAQUA, Universidad de Las Palmas de Gran Canaria, Las Palmas de Gran Canaria, Spain

${ }^{g}$ Centre for Coastal Research, Department of Natural Sciences, University of Agder, Kristiansand, Norway

${ }^{\mathrm{h}}$ GEOMAR Helmholtz Centre for Ocean Research Kiel, Kiel, Germany
}

\section{H I G H L I G H T S}

- Effects of rising atmospheric $\mathrm{CO}_{2}$ on zooplankton were studied in coastal mesocosms.

- Mesozooplankton metabolism was more affected by elevated $\mathrm{CO}_{2}$ than microzooplankton.

- $\mathrm{CO}_{2}$-induced effects were more marked in eutrophic than in oligotrophic conditions.

- Elevated $\mathrm{CO}_{2}$ impacts the role of zooplankton on the carbon and nitrogen cycles.
G R A P H I C A L A B S T R A C T

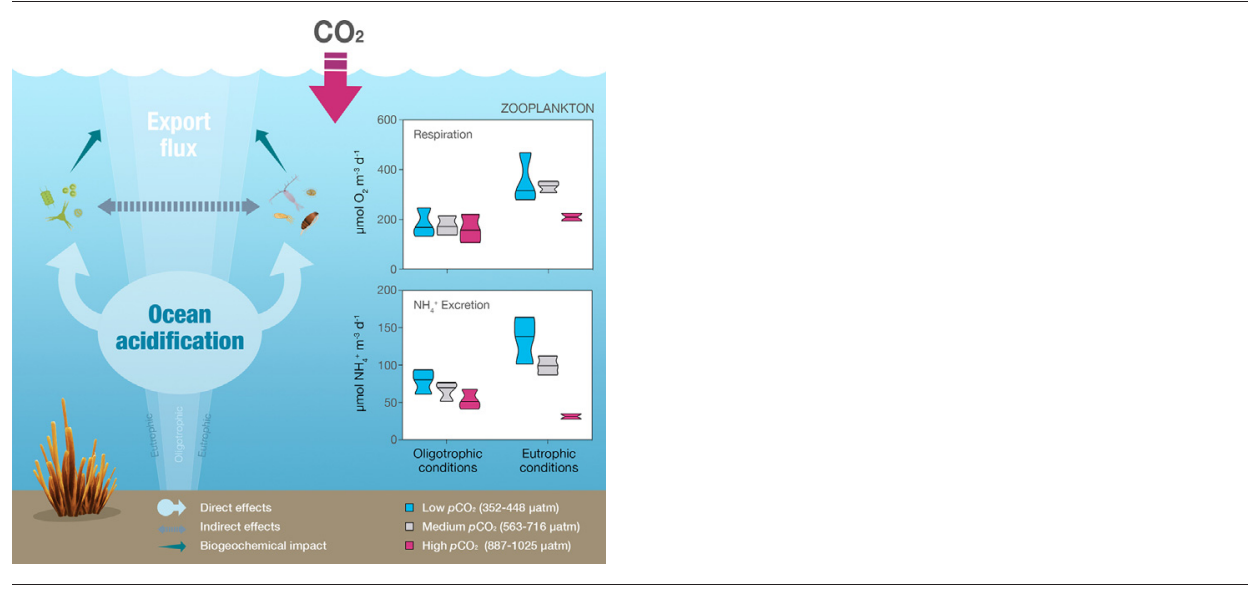

A B S T R A C T

Ocean acidification (OA) is one of the most critical anthropogenic threats to marine ecosystems. While significant ecological responses of plankton communities to OA have been revealed mainly by small-scale laboratory approaches, the interactive effect of OA-related changes on zooplankton metabolism and their biogeochemical implications in the natural environment still remains less well understood. Here, we explore the responses of zooplankton respiration and ammonium excretion, two key processes in the nutrient cycling, to high $p \mathrm{CO}_{2}$ levels in a 9-week in situ mesocosm experiment conducted during the autumn oligotrophic season in the subtropical northeast Atlantic. By simulating an upwelling event halfway through the study, we further evaluated the combined effects of OA and nutrient availability on the physiology of micro-and mesozooplankton. OA conditions generally resulted in a reduction in the biomassspecific metabolic and enzymatic rates, particularly in the mesozooplankton community. The situation reversed after the nutrient-rich deep-water addition, which initially promoted a diatom bloom and increased heterotrophic activities

* Correspondence to: N. Osma, Department of Aquatic Systems, Faculty of Environmental Science, Universidad de Concepción, Concepción, Chile.

** Corresponding author.

E-mail addresses: natalia.osma@imo-chile.cl (N. Osma), igor.fernandez@imo-chile.cl (I. Fernández-Urruzola). 
Zooplankton community

Metabolism

Enzymatic rates in all mesocosms. Under high $p \mathrm{CO}_{2}$ conditions ( $>800 \mu \mathrm{atm}$ ), however, the nutrient fertilization triggered the proliferation of the harmful alga Vicicitus globosus, with important consequences for the metabolic performance of the two zooplankton size classes. Here, the zooplankton contribution to the remineralization of organic matter and nitrogen regeneration dropped by $30 \%$ and $24 \%$, respectively, during the oligotrophic period, and by $40 \%$ and $70 \%$ during simulated upwelling. Overall, our results indicate a potential reduction in the biogeochemical role of zooplankton under future ocean conditions, with more evident effects on the large mesozooplankton and during high productivity events.

\section{Introduction}

The global ocean takes up about one quarter of anthropogenic $\mathrm{CO}_{2}$ emissions every year (Le Quéré et al., 2016). This leads to a pronounced shift in seawater carbonate chemistry and a decrease in the $\mathrm{pH}$, a process well known as ocean acidification (OA; Caldeira and Wickett, 2003). OA is projected to cause a further reduction of seawater $\mathrm{pH}$ of $0.1-0.4$ units by the end of the century (Orr et al., 2005), which may substantially impact the physiological performance of marine biota with far-reaching implications at the ecosystem level (Kroeker et al., 2013; Wittmann and Pörtner, 2013).

Research on $\mathrm{CO}_{2}$-related effects on marine organisms has experienced a remarkable rise over the past decade (Gattuso and Hansson, 2011). Laboratory-scale studies, with cultures of single species and/or with artificial predator-prey interactions, provide valuable information about the mechanistic processes involved in the species-specific responses to OA. The number of studies evaluating OA impacts at the level of communities and ecosystems, although it is increasingly growing, is still comparatively lower (Riebesell and Gattuso, 2015). The advantage of these community-based experiments is that they include indirect effects of OA through ecological interactions and thus allow for a more representative assessment of ecosystem impacts of OA. In this regard, large-volume in situ mesocosms experiments have emerged as a suitable tool to investigate the impact of environmental drivers on pelagic community dynamics in a close-to-natural environment (Riebesell et al., 2013).

Within the highly complex ecological network of pelagic food webs, zooplankton communities play a pivotal role. These organisms are key in controlling the development of phytoplankton blooms, influencing both the magnitude and the efficiency of the biological pump, and at the same time, they provide a trophic link to higher level consumers (Longhurst and Harrison, 1989). Previous studies using in situ mesocosms have mainly focused on determining changes in the abundance and taxonomic composition of zooplankton (e.g. Aberle et al., 2013; Algueró-Muñiz et al., 2017), whereas the impact on their physiology has received much less attention. Through their metabolism, zooplankton contributes substantially to remineralization of organic matter and to nutrient regeneration in marine ecosystems (Steinberg and Landry, 2017). The two principal catabolic processes involved in nutrient cycling are the respiration $\left(\mathrm{RO}_{2}\right)$ and ammonium excretion $\left(\mathrm{RNH}_{4}^{+}\right)$. At the intracellular level, $\mathrm{RO}_{2}$ and $\mathrm{RNH}_{4}^{+}$are the direct result of the enzymatic activities of the electron transport system (ETS; Packard et al., 1971) and the glutamate dehydrogenase (GDH; Bidigare and King, 1981) enzyme, respectively. The measurement of these enzymatic rates determines the maximum capacity at which these enzymes can operate, or in other words, the maximum oxygen consumption or ammonium production organisms can have. Both physiological and enzymatic rates are stoichiometrically related and, as such, the latter are widely used to explore the respiratory and excretory metabolisms in a plethora of organisms and marine ecosystems when direct measures are unfeasible (Belcher et al., 2020; Fernández-Urruzola et al., 2014; Osma et al., 2016a). The constitutive nature of these enzymes, however, makes their potential activities respond more slowly to external stimuli than do the instantaneous physiological rates, thereby causing variability in their relationship (i.e., in the $R \mathrm{O}_{2}$ /ETS and $\mathrm{RNH}_{4}^{+} / \mathrm{GDH}$ ratios). This results from efficient regulation mechanisms that prevent short-term fluctuations in the enzyme pools when sudden environmental changes occur (Fernández-Urruzola et al., 2016a; Osma et al., 2016b). Only if these environmental changes persist, may there be an effective biochemical adaptation in the enzyme levels. Whether OA-related stress sustained over time leads to biochemical shifts in the zooplankton ETS and GDH, however, is largely unknown.

Growing experimental evidence on the organism level suggests direct effects of OA on zooplankton metabolism through changes in the intracellular $\mathrm{pH}$ and the cell membrane potential (Nielsen et al., 2010). Organismal homeostasis must be then achieved through costly acid-base regulatory processes that reduce resource allocation to other biological processes (Wang et al., 2018), unless there is sufficient food intake that may compensate this reduction to a certain extent. Moreover, OA may indirectly affect the zooplankton physiology by modifying the amount and quality of their prey (Meunier et al., 2016). Bottom-up effects of OA are mostly associated with interspecific differences in the sensitivity of phytoplankton to elevated $p \mathrm{CO}_{2}$ levels, resulting in changes in the community structure (Bach et al., 2016) and in the elemental stoichiometry of primary producers (Meunier et al., 2016). Altogether these functional responses to low seawater $\mathrm{pH}$ at the base of the food web influence the diet of zooplankton and, ultimately, the percentage composition of substrates (i.e., carbohydrates, lipids and proteins) metabolized for energy in their cells (Rossoll et al., 2012). Although our understanding of zooplankton performance under OA has greatly improved through controlled microcosm approaches, the combined effect of all OA-induced changes on the zooplankton metabolism is still poorly known. Hence, the biogeochemical consequences at the community level are uncertain. To this aim, we set up a more complex, 9-week mesocosm-based field experiment, which allowed us to evaluate ecological responses of a natural plankton community from the subtropical NE Atlantic to simulated OA conditions. Here we focus specifically on investigating potential changes in the zooplankton respiratory and excretory activities caused by OA and how these might affect the cycling of organic matter in future OA scenarios. We consider two size classes of zooplankton, the microzooplankton $(55-200 \mu \mathrm{m})$ and the mesozooplankton (200-2000 $\mu \mathrm{m})$, because they play different ecological roles in the pelagic ecosystems and, therefore, they may be subjected to distinct OAeffects.

The research was conducted in the oligotrophic system off the east coast of Gran Canaria (Spain). Subtropical oligotrophic waters represent the largest ecosystem in the surface ocean (Longhurst et al., 1995), and yet the response of their plankton communities to predicted OA has been comparatively understudied so far. In fact, these regions deserve particular attention given the more pronounced effects that high $p \mathrm{CO}_{2}$ levels have on ecosystem processes when inorganic nutrient concentrations are low (Bach et al., 2016; Paul et al., 2015; Sala et al., 2015). The marine waters where the mesocosms were deployed are nutrientlimited most of the year, although they receive sporadic inputs of nutrients through island-induced eddies and upwelling filaments coming from NW Africa, promoting occasional phytoplankton blooms in the region (Arístegui et al., 2001; Sangrà et al., 2009). Therefore, in addition to simulated OA conditions, the experiment reproduced these natural fertilization events by adding a known volume of deep-water, rich in nutrients, into the mesocosms half-way through the investigation. The experimental design thus provided a basis for evaluating zooplankton responses to OA under variable productivity regimes that are typically found in the study area. Since compensatory feeding may ameliorate to some extent the negative effects of elevated $p \mathrm{CO}_{2}$ on the metabolism, we hypothesized that zooplankton respiration and ammonium excretion will be less affected by increased $\mathrm{CO}_{2}$ levels under the eutrophic 
conditions than under oligotrophic conditions. Accordingly, we further hypothesized that the contribution of zooplankton to the remineralization of organic matter and nutrient cycling will be higher after the simulated upwelling event, when we expected to observe a phytoplankton bloom, than under the initial oligotrophic conditions.

\section{Methods}

\subsection{Experimental design}

In autumn 2014, we conducted an in situ off-shore mesocosm experiment as part of the BIOACID (Biological Impacts of Ocean ACIDification) project, hosted by the Plataforma Oceánica de Canarias (PLOCAN). A total of 9 pelagic mesocosms (M1-M9, KOSMOS: Kiel Offshore Mesocosms for Future Ocean Simulation; Riebesell et al., 2013) were deployed in Gando Bay $\left(27^{\circ} 55^{\prime} 41^{\prime \prime} \mathrm{N}, 15^{\circ} 21^{\prime} 55^{\prime \prime} \mathrm{W}\right)$, Gran Canaria (Canary Islands), to study the effects of OA in an oligotrophic subtropical plankton community (see Supplementary Fig. A.1). The location was a relatively shallow coastal area of 30-40 depth, whose orientation further protected the mesocosms from the northeast trade winds. Each $15 \mathrm{~m}$ long mesocosm enclosed $35 \mathrm{~m}^{3}$ water volume and consisted of a cylindrical bag (13 $\mathrm{m}$ long, $2 \mathrm{~m}$ diameter) sealed at the bottom by a conical sediment trap $(2 \mathrm{~m})$. The experiment started on September 27 (t-4), with the closure of the mesocosms 4 days before the first $\mathrm{CO} 2$ addition (t0), and finished on November 26 (t56). The experimental time-frame was chosen on the basis of the environmental conditions in the region: (i) the intensity of the trade winds is weaker during autumn (e.g., Marrero-Betancort et al., 2020), which was important to prevent damage to the mesocosms' structure; (ii) the combination of warm sea-surface temperatures and weak winds results in stratified and stable water columns at this time of the year (Schmoker and Hernández-León, 2013); (iii) the water column stratification further ensured the required oligotrophic conditions to start the experiment. Unfortunately, despite all the precautions taken, one mesocosm (M6) was damaged on t27 due to strong currents, and was excluded from sampling and analysis from that day on.

The mesocosms were first sampled before $p \mathrm{CO}_{2}$ manipulation to ensure similar physico-chemical conditions. The initial differences for temperature, salinity, $\mathrm{pH}$, chlorophyll and nutrients between mesocosms were small (see Taucher et al., 2017), mostly within the uncertainty of the measurements. Mesocosms were then treated with different amounts of $\mathrm{CO}_{2}$ enriched seawater according to the protocol described by Riebesell et al. (2013), to set up a gradient of $p \mathrm{CO}_{2}$ ranging from ambient levels $(\sim 350 \mu \mathrm{atm})$ to partial pressures predicted by the RCP8.5 scenario $\left(\sim 1000 \mu \mathrm{atm}\right.$; IPCC, 2013). Target $p \mathrm{CO}_{2}$ levels at the beginning of the experiment were achieved by gradually adding $\mathrm{CO}_{2}$-saturated seawater in four steps over 7 days. Two more $\mathrm{CO}_{2}$ additions were performed on $\mathrm{t} 21$ and $\mathrm{t} 38$ to compensate the $\mathrm{CO}_{2}$ loss through air-water gas exchange. M1 and $\mathrm{M} 9$ served as controls (ambient $p \mathrm{CO}_{2}$ levels) and were not $\mathrm{CO}_{2}$ manipulated. The mean $p \mathrm{CO}_{2}$ values per mesocosm for the full duration were $\mathrm{M} 1=369, \mathrm{M} 2=887, \mathrm{M} 3=563, \mathrm{M} 4=716, \mathrm{M} 5=448, \mathrm{M} 6=976$ (phase I), M7 = 668, M8 = 1025 and M9 = $352 \mu$ atm (Supplementary Table A.1). On the basis of a k-means cluster analysis, mesocosms were grouped into three $\mathrm{pCO}_{2}$-treatments to facilitate the quantitative description of the data (Algueró-Muñiz et al., 2019): low- $p \mathrm{CO}_{2}$ (M1, M5, M9), medium- $p \mathrm{CO}_{2}(\mathrm{M} 3, \mathrm{M} 4, \mathrm{M} 7)$ and high- $p \mathrm{CO}_{2}(\mathrm{M} 2, \mathrm{M} 6, \mathrm{M} 8)$ (Supplementary Table A.1).

In order to simulate the eventual influence of nutrient-rich waters on this predominantly oligotrophic ecosystem, about $20 \%$ of mesocosm water was replaced on 24 with nutrient-rich deep-water collected from $650 \mathrm{~m}$ at a nearby location $(\sim 7 \mathrm{~km}$ north-east from the study site, $1000 \mathrm{~m}$ depth). After this deep-water addition, the average concentration of inorganic nutrients in the mesocosms increased up to 50 -fold, reaching values of $3.15,0.17$, and $1.60 \mu \mathrm{mol} \mathrm{L}^{-1}$ for $\mathrm{NO}_{\mathrm{x}}^{-}, \mathrm{PO}_{4}^{3-}$, Si $(\mathrm{OH})_{4}$, respectively. A more detailed description of the technical aspects of $p \mathrm{CO}_{2}$ manipulation and deep-water addition can be found in Taucher et al. (2017).

\subsection{Sampling and sample processing}

Sampling program included CTD casts, water column samplings and sediment traps samplings that were conducted between 9 am and $12 \mathrm{pm}$ every second day, except during phase II, where samples were taken every day. Vertical profiles of CTD (CTD60M, Sea and Sun Technologies) performed in each mesocosm and in the surrounding waters (Atlantic), revealed a well-mixed water column inside the mesocosm throughout the entire experiment (Taucher et al., 2017). Water samples were collected using two sampling systems: (1) a depth-integrating water sampler (IWS, Hydrobios, Kiel) for samples sensitive to gas exchange or contamination (e.g. carbonate chemistry parameters and nutrients), and (2) a custombuilt vacuum pumping system connected to 20 L-carboys for samples that required larger amounts of water, including phytoplankton pigments, total particulate organic carbon, nitrogen and phosphorus, as well as counts of bacterial, virus and phytoplankton group abundances. All carboys were sunlight-protected during sampling and stored in a cold room set to $16^{\circ} \mathrm{C}$ upon arrival at the PLOCAN facilities. After carefully mixing these carboys to avoid particle sedimentation, subsamples for chl-a were collected, filtered onto glass fiber filters (GF/F Whatman, nominal pore size $0.7 \mu \mathrm{m}$ ) and analyzed by reverse-phase high-performance liquid chromatography. Nutrients (nitrate + nitrite, (i.e., $\mathrm{NO}_{\mathrm{x}}$ )) were measured using an autoanalyzer (SEAL Analytical, QuAAtro) coupled to an autosampler (SEAL Analytical, XY2). $\mathrm{NO}_{\mathrm{x}}$ represents a proxy for inorganic nitrogen oxide concentration during the experiment; for further details on $\mathrm{PO}_{4}^{3-}$, $\mathrm{Si}(\mathrm{OH})_{4}$ and $\mathrm{NH}_{4}^{+}$dynamics see Taucher et al. (2017). Partial pressure of $\mathrm{CO}_{2}\left(p \mathrm{CO}_{2}\right)$ was derived from total alkalinity and dissolved inorganic carbon using CO2SYS (Pierrot et al., 2006). The abundance of the toxic algae $V$. globosus in the medium- and high- $\mathrm{pCO}_{2}$ mesocosms was determined by direct cell counts in acidic Lugol-fixed samples collected with the IWS and analyzed by the Utermöhl technique (Utermöhl, 1958). V. globosus was the only toxic algae present in the phytoplankton samples that reached harmful algal bloom (HAB) levels during our study, although a minor presence of other species was detected. Microzooplankton samples for taxonomic analysis were also sampled every 8 days with the IWS and included the $20-200 \mu \mathrm{m}$ size fraction. These samples were preserved with acidic Lugol's solution and stored in brown glass bottles in the dark until measurement. Abundances of the major groups were determined by the Utermöhl technique (Utermöhl, 1958).

Zooplankton was sampled at 8-day intervals with an Apstein net (55 $\mu \mathrm{m}$ mesh size, $0.17 \mathrm{~m}$ diameter opening) equipped with a closed cod end. This sampling frequency was chosen in order to avoid depleting the zooplankters in the mesocosms. The maximum sampling depth of net tows was $13 \mathrm{~m}$ to prevent resuspension of the sedimented material, resulting in a sampling volume of $0.295 \mathrm{~m}^{3}$. Samples were kept in a cooling box during the sampling and transport to the on-shore laboratory, where they awaited processing in a temperature-controlled room $\left(16^{\circ} \mathrm{C}\right)$. Zooplankton for metabolic analysis were gently fractionated with a mesh in two size fractions, microzooplankton $(55-200 \mu \mathrm{m})$ and mesozooplankton $(>200 \mu \mathrm{m})$. Note that the lower limit of the microzooplankton size range was constrained by the mesh fitted to the net, and it did not correspond with the classical range $(20-200 \mu \mathrm{m})$. The microzooplankton samples were thoroughly washed by flushing with filtered seawater to prevent contamination by phytoplankton. This washing procedure is usually sufficient to break diatom-chains and get rid of those long cells with reduced widths, like the ones that dominated during our study (i.e. Guinardia striata, Leptocylindrus danicus and Nitzschia sp.; Taucher et al., 2018). During the bloom phase (t25 and t33), when phytoplankton cells were most abundant in the mesocosms, we double checked the microzooplankton samples and performed a visual inspection of them in a stereomicroscope (Olympus SZX9), which confirmed only a residual presence of phytoplankton cells. All microzooplankton samples as well as mesozooplankton samples from M1, M3, M4, M6 (phase I) and M8 mesocosms were immediately frozen in liquid nitrogen and stored at $-80^{\circ} \mathrm{C}$ for the subsequent determination of the biochemical parameters. Mesozooplankton samples for incubations (M2, M5, M7, M9) awaited in the cold room until analyzed ( $<4 \mathrm{~h}$ ). Samples 
for taxonomic analysis collected by the nets were preserved in denatured ethanol and quantified and classified to the lowest possible taxonomic level as described by Algueró-Muñiz et al., 2019. Note that nauplii were included in the mesozooplankton size fraction since they were counted from the net hauls ( $>55 \mu \mathrm{m}$ ), although they strictly belong to microzooplankton according to Sieburth et al.'s (1978) size definition.

\subsection{Biochemical parameters}

The potential respiration and potential $\mathrm{NH}_{4}^{+}$excretion rates of zooplankton over the experimental period were assessed by measuring the electron transport system (ETS) and glutamate dehydrogenase (GDH) activities, respectively. Samples were first thawed, sonicated for $45 \mathrm{~s}$ (70\% amplitude) in $0.1 \mathrm{M}$ phosphate buffer ( $\mathrm{pH}$ 8.5) and the homogenates, centrifuged for $8 \mathrm{~min}$ at $4000 \mathrm{rpm}$. Both enzymatic assays were immediately performed on subsamples of the supernatants, always at saturated concentrations of their specific substrates to ensure the reproducibility and specificity of the reactions. The whole procedure was done in ice-cold to prevent a decline in the enzyme activities. The ETS activity was measured kinetically according to Owens and King (1975) with the modifications described by Packard et al. (1996). The increase in absorbance at $490 \mathrm{~nm}$ due to the production of INT-formazan in the cuvette is stoichiometrically related to oxygen consumption (Packard and Williams, 1981). The GDH activity was determined from the fluorometric quantification of NADH production from glutamate catabolism using the method of Bidigare and King (1981), as modified by Fernández-Urruzola et al. (2011), and directly calibrated against pure GDH (1.4.1.3). The relationship between the ETS and GDH activities (O/N ratio) was further calculated as a proxy for the organic compounds oxidized for energy (Mayzaud and Conover, 1988).

Protein content was also analyzed in aliquots from all homogenates as a measure of biomass. Analyses were done by triplicate following the Lowry's protocol (Lowry et al., 1951), adapted for micro-assay by Rutter (1967), which provides good sensitivity over the protein concentration range considered here. Bovine serum albumin was used as standard.

\subsection{Zooplankton incubations}

Mesozooplankton collected at different $p \mathrm{CO}_{2}$ treatments was additionally incubated for the direct measure of respiration and $\mathrm{NH}_{4}^{+}$excretion rates. Samples included zooplankton exposed to low (M5 and M9), medium (M7) and high (M2) $p \mathrm{CO}_{2}$ levels (see Supplementary Table A.1). We considered organisms from 2 mesocosms at current $p \mathrm{CO}_{2}$ levels to reduce the risk of ending up without a control sample in case any of the mesocosms got lost during the experiment due to adverse-weather conditions. Organisms were acclimated prior to incubation in order to reduce the stress during the sampling course. Acclimation was carried out in a light trap, consisting of a dark bottle connected through its base to the top of a clear one, both filled with filtered seawater at in situ temperature and $\mathrm{pCO}_{2}$. Owing to a positive phototaxis, the healthy specimens swam actively and moved to the illuminated bottle before $1 \mathrm{~h}$. Only a few dead individuals together with some detritus remained in the dark bottle. A representative mixed sample of those active organisms were then gently siphoned into $60 \mathrm{~mL}$ gas-tight glass bottles partially filled with filtered seawater at the desired $p \mathrm{CO}_{2}$ level, and incubated in the dark for 2-3 h. All batches included 3 experimental bottles (as long as there was enough biomass) and 1 control flask without organisms. Dissolved oxygen was continuously monitored in each bottle with installed oxygen electrodes (Strathkelvin 928 Oxygen System ${ }^{\circledR}$ respirometer), whereas the $\mathrm{NH}_{4}^{+}$concentration was determined before and after the incubation following the phenol-hypochlorite method (Solorzano, 1969). Organisms were then frozen in liquid nitrogen for subsequent analyses of the protein content as well as of the ETS and GDH activities.

\subsection{Statistical analysis}

To evaluate the potential overall effect of increased $\mathrm{pCO}_{2}$ levels on zooplankton metabolism throughout the three experimental phases, we applied simple linear regression analyses between the $p \mathrm{CO}_{2}$ values in the mesocosms and the response of the variables for each phase using GraphPad Prism (v8.4, GraphPad software, San Diego, USA). The model outputs were checked for normality and homoscedasticity. The confidence level for all analysis was set at $95 \%(p<0.095)$.

We further studied the variability of the biological parameters (protein, ETS, GDH, spcETS, spcGDH, and the ratios $\mathrm{RO}_{2} / \mathrm{ETS}, \mathrm{RNH}_{4}^{+} / \mathrm{GDH}$ and O/ $\mathrm{N})$ during the three experimental phases and between the three $p \mathrm{CO}_{2}$ treatments using a two-way ANOVA test, both in microzooplankton and mesozooplankton (Supplementary Tables A.2 and A.3, respectively.). Prior to analysis, all dependent variables were tested for normality and $\log (x+1)$-transformed when needed, and the homogeneity of variance was assessed using the Levene's test. Each comparison was tested using the corrected significance level according to the Bonferroni method. Significant differences (significance level at 0.05 ) were further analyzed using the pairwise comparison procedure of the Tukey HSD Post-Hoc test. These analyses were conducted using the statistical software SPSS (v.26, SPSS Inc., 2010, Chicago, IL, USA).

\section{Results}

\subsection{Environmental and ecological conditions}

In view of the nitrate + nitrite $\left(\left[\mathrm{NO}_{x}\right]\right)$ and the chl-a concentration time-courses (Fig. 1), we could differentiate three well-defined phases: the initial oligotrophic pre-bloom phase (I), from t1 to t23; the bloom phase (II), from t 25 to $t 35$ (after addition of nutrient-rich deep water on day 24); and the post-bloom phase (III), from $t 35$ until the end of the experiment on $\mathrm{t} 55$. Both temperature and salinity remained practically constant over the three phases, with average $( \pm S D)$ values of $23.6 \pm 0.6{ }^{\circ} \mathrm{C}$ and $37.6 \pm 0.2$ (unitless), respectively. The experiment started under oligotrophic conditions, with very low and constant concentrations of inorganic nutrients $\left(\left[\mathrm{NO}_{x}\right]<0.1 \mu \mathrm{M}\right)$ and chl-a $\left(<0.2 \mathrm{mg} \mathrm{m}^{-3}\right)$ (Fig. $1 \mathrm{~b}$ and c). The nutrient-rich deep-water addition on $\mathrm{t} 24$ stimulated phytoplankton growth, reaching a chl-a peak of $\sim 3.2 \mathrm{mg} \mathrm{m}^{-3}$ on t28. After this peak, the chl-a decreased to a minimum on $\mathrm{t} 35$ and remained low until the end of the experiment, except for the high- $\mathrm{pCO}_{2}$ mesocosms, which showed a moderately elevated chl-a (0.5-1.4 $\mathrm{mg} \mathrm{m}^{-3}$ ) during the post-bloom phase (Fig. 1c).

The phytoplankton species composition during the oligotrophic conditions of phase I evolved from a picocyanobacteria-dominated community (70-80\% of total chl-a) to a more mixed one, including diatoms, prymnesiophytes, cryptophytes and cyanobacteria, among others (Taucher et al., 2018; this study, Supplementary Fig. A.2). Afterwards, the deep water-induced phytoplankton bloom was largely constituted by large chain-forming diatoms, which continued to be the dominant group toward the end of the experiment, even though their relative contribution to total chl-a and cell density decreased during the post-bloom phase $(<50 \%)$. One exception to this trend was observed on the high- $p \mathrm{CO}_{2}$ mesocosms, where diatom biomass and relative abundance remained high (70-80\%) until the end of the experiment. Furthermore, increased nutrient concentrations promoted the proliferation of the toxic phytoplankton species Vicicitus globosus (Riebesell et al., 2018; this study, Fig. 1d) in the high- $\mathrm{pCO}_{2}$ mesocosms, reaching cell densities of $600-800$ cell mL $^{-1}$ and contributing significantly to the total chl-a (up to $25 \%$ ) during phase II. The bloom of V. globosus ended on $\mathrm{t} 47$.

Supplementary Fig. A. 3 shows the abundances of the zooplankton groups that contributes more than $5 \%$ to the total abundance, which together accounts for more than $93 \%$ to the total zooplankton abundance throughout the experiment. The zooplankton community was largely dominated by aloricate ciliates and heterotrophic/mixotrophic dinoflagellates in the smallest size fraction (i.e. microzooplankton), and by calanoid copepods and copepod nauplii in the largest size fraction (i.e. mesozooplankton), although their relative abundance varied between phases and treatments (Algueró-Muñiz et al., 2019; Supplementary Fig. A.3, this study). Copepods were primarily represented by the genera Paracalanus, Clausocalanus, Oithona and Oncaea. To a lesser extent, other 

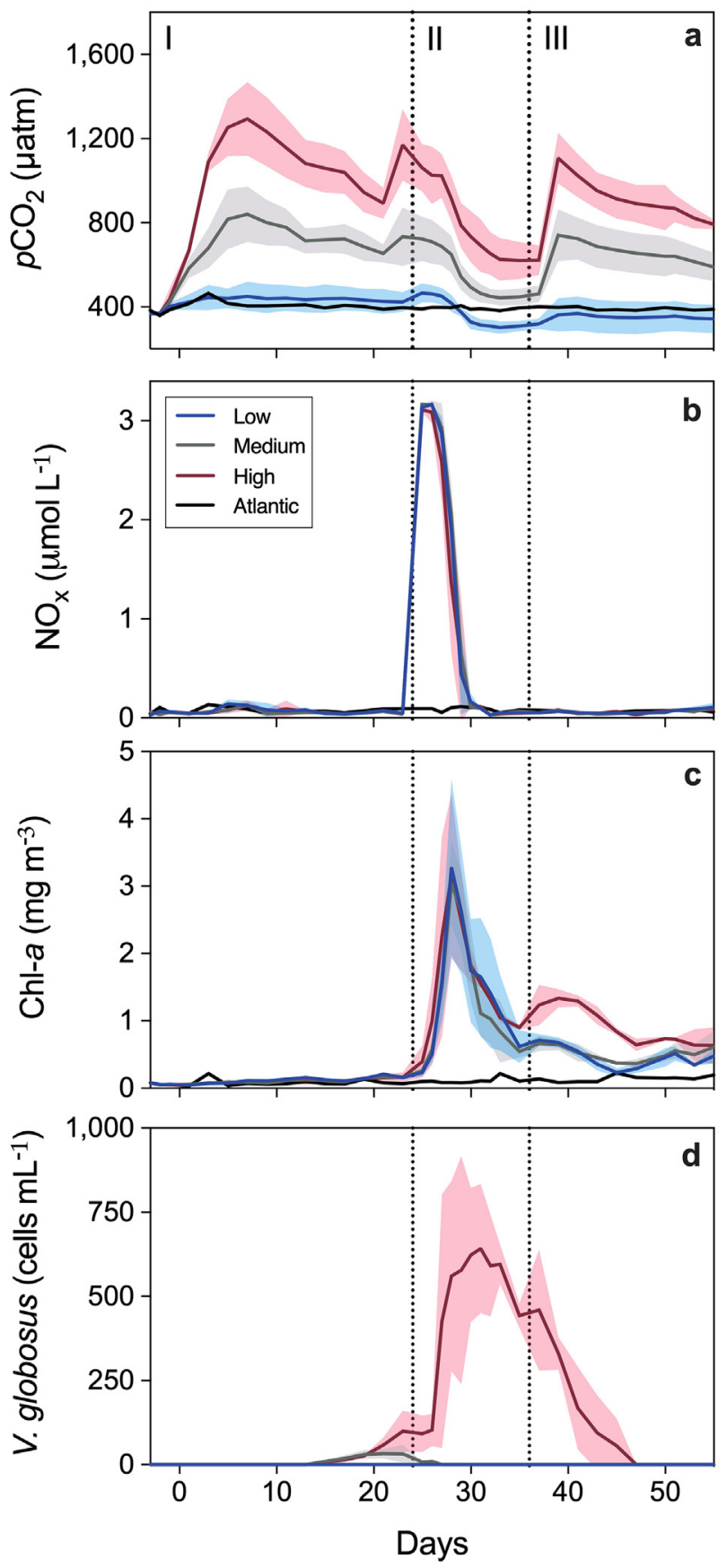

Fig. 1. $p \mathrm{CO}_{2}$ level (a), nitrate + nitrite concentration $\left(\mathrm{NO}_{x}\right)$ (b), chlorophyll $a$ concentration (chl-a) (c) and abundance of the toxic algae Vicicitus globosus (d) averaged for the three $p \mathrm{CO}_{2}$ treatments (low, medium and high) over the course of the study. Light color shadows represent the standard deviation of the mean. The corresponding values measured in the surrounding open waters (Atlantic) are also given as a reference. Dotted vertical lines indicate the different phases of the experiment: (I) oligotrophic, (II) bloom and (III) post-bloom (see Supplementary Table A.1).

abundant groups included tunicates, which were represented by the Appendicularia Oikopleura dioica and Doliolids (Doliolum sp.), and foraminifera from the family Globigerinidae (Lischka et al., 2018; Supplementary Fig. A.3, this study). A detailed examination of the zooplankton community structure can be found in the papers by Lischka et al. (2018), Stange et al. (2018) and Algueró-Muñiz et al. (2019). The average zooplankton abundances (except for foraminifera) were lower during oligotrophic conditions than after the deep-water addition. Most zooplankton groups responded rapidly to the phytoplankton bloom in the low- and medium- $p \mathrm{CO}_{2}$ treatments and increased 3-fold their abundance. In the high-p $\mathrm{CO}_{2}$ treatment, in contrast, the abundance of most groups decreased to pre-bloom levels in response to the growth of $V$. globosus and remained low until the bloom of this toxic algae ended.

\subsection{Temporal development of zooplankton metabolism}

Response variables showed distinct patterns in micro- and mesozooplankton over the respective experimental phases (Fig. 2; Supplementary Tables A.2 and A.3). During oligotrophic conditions, microzooplankton biomass, ETS activity and GDH activity remained low and fairly constant in the mesocosms and did not differ between $\mathrm{CO}_{2}$-treatments, with average values of $0.62 \pm 0.41 \mathrm{mg}$ prot $\mathrm{m}^{-3}, 45.05 \pm$ $25.47 \mu \mathrm{mol} \mathrm{O} \mathrm{m}^{-3} \mathrm{~d}^{-1}, 9.64 \pm 4.68 \mu \mathrm{mol} \mathrm{NH}_{4}^{+} \mathrm{m}^{-3} \mathrm{~d}^{-1}$, respectively. However, biomass-specific enzymatic rates revealed an overall decreasing trend during this phase (Fig. 3). Following the chl-a build-up on t28, microzooplankton biomass and ETS activity increased rapidly in all mesocosms, reaching maximum values on $t 41$ (Phase effect, two-way ANOVA, Supplementary Table A.2), to then decrease again toward the end of the experiment. Even though the GDH activity also increased after the phytoplankton bloom, this increase was delayed 8 days and was of lower magnitude in the medium- and high- $p \mathrm{CO}_{2}$ mesocosms. This effect was likewise reflected in the spc-GDH activity during phase II, which then showed a significant increase until the end of experiment (Phase effect, two-way ANOVA, Supplementary Table A.2). Maximum values for spc-ETS activities were recorded on the last sampling day in the low and medium- $p \mathrm{CO}_{2}$ mesocosms (average of $114.0 \pm 25.2 \mu \mathrm{mol} \mathrm{O}_{2} \mathrm{mg}^{-1}$ prot $\mathrm{d}^{-1}$ ), whereas the peak value for the spc-GDH activity $\left(39.3 \pm 7.1 \mu \mathrm{mol} \mathrm{NH}{ }_{4}^{+} \mathrm{mg}^{-1}\right.$ prot d $\left.{ }^{-1}\right)$ was measured on t50 under medium $\mathrm{pCO}_{2}$ levels (Fig. 3).

Mesozooplankton biomass and enzymatic rates in the mesocosms behaved differently between phases and treatments (Fig. 2d-f, Supplementary Tables A.3). While proteinaceous biomass and ETS activity displayed a moderate decrease during oligotrophic conditions, GDH activity showed an increase halfway through this phase. After the phytoplankton bloom, biomass and enzymatic activities in the low and medium- $-\mathrm{CO}_{2}$ mesocosms started to increase until a maximum on $\mathrm{t} 41$, decreasing again toward the end of the experiment. Unlike in microzooplankton, where peak values during phase III were 5-6 times higher than those measured during phase I, in mesozooplankton, peak values during phase III were similar (ETS) or significantly lower (biomass and GDH) to the maximum values recorded during phase I (Phase effect, two-way ANOVA, Supplementary Table A.3). Furthermore, neither the biomass nor the enzymatic activities in mesozooplankton responded positively to the phytoplankton bloom in the high- $\mathrm{CO}_{2}$ mesocosms (Treatment effect, two-way ANOVA, Supplementary Table A.3). Instead, they decreased to minimum during phase II and remained at significantly lower levels until the end of the experiment.

The response of mesozooplankton biomass-specific enzymatic activities and physiological rates was more variable (Fig. 4), with the spcETS showing a significant interaction between the phases and treatments (two-way ANOVA, Supplementary Table A.3). Organisms at $p \mathrm{CO}_{2}$ levels $<800 \mu \mathrm{atm}$ showed an increase in the enzymatic and physiological rates under oligotrophic conditions which, in general terms, peaked earlier in the low$p \mathrm{CO}_{2}$ (t9) than in the medium- $p \mathrm{CO}_{2}$ mesocosms (t17). Mesozooplankton at high- $p \mathrm{CO}_{2}$ levels, in contrast, showed significantly lower values (Treatment effect, two-way ANOVA, Supplementary Table A.3) and displayed an overall decreasing trend of all rates during this phase. After deepwater addition, both $\mathrm{RO}_{2}$ and $\mathrm{RNH}_{4}^{+}$responded rapidly to the phytoplankton bloom, increasing readily during phase II, while spc-ETS and spc-GDH activities remained low until the beginning of the post-bloom phase. All specific rates increased during the last phase of the experiment at $p \mathrm{CO}_{2}$ levels $<800 \mu \mathrm{atm}$, with peak values at $\mathrm{t} 41$ (medium- $p \mathrm{CO}_{2}$ ) and t50 (low$p \mathrm{CO}_{2}$ ). However, at high- $p \mathrm{CO}_{2}$ levels, the spc-ETS activity and $\mathrm{RO}_{2}$ did not display an increase and stayed low until the end of the experiment, while the spc-GDH activity and $\mathrm{RNH}_{4}^{+}$increased after the abundance of $V$. globosus started to decline (Fig. 1c), reaching maximum values on the last sampling day (t55). 
Microzooplankton (55-200 $\mu \mathrm{m})$
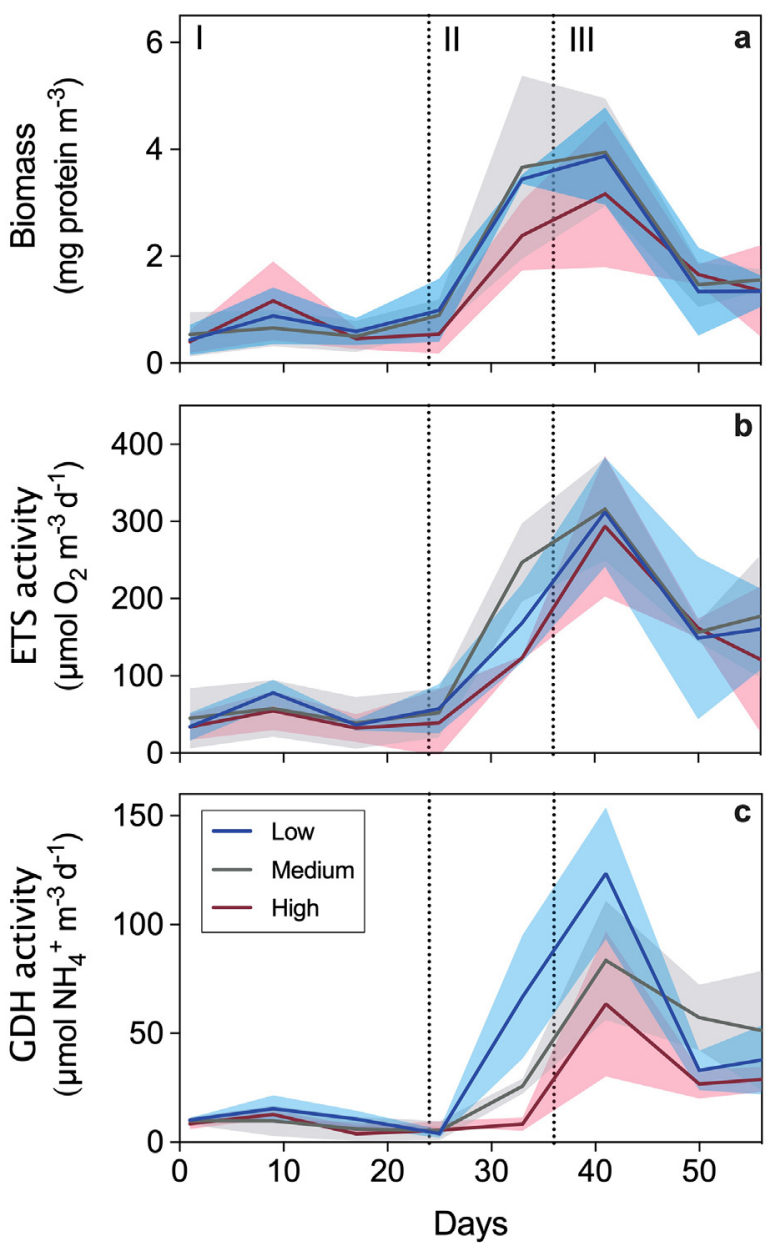

Mesozooplankton (> $200 \mu \mathrm{m})$
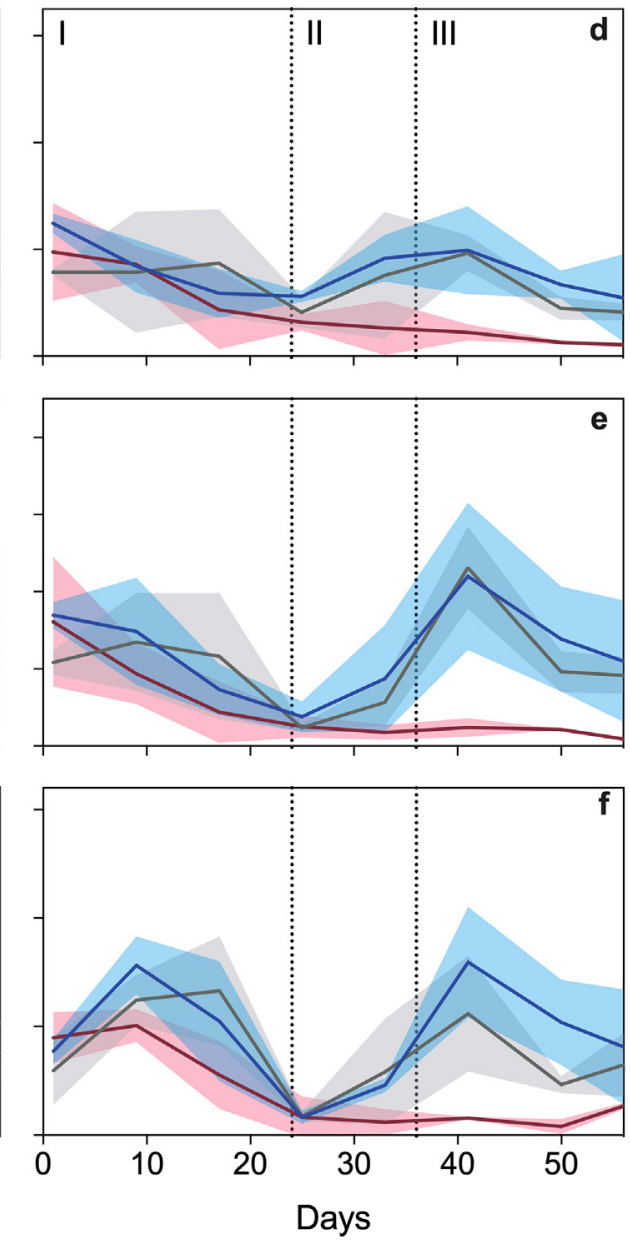

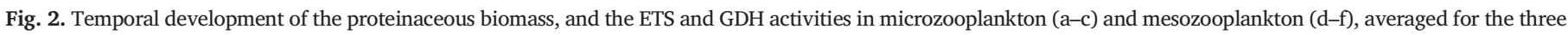
$p \mathrm{CO}_{2}$ treatments. Light color shadows represent the standard deviation of the mean. Dotted vertical lines indicate the three phases during the experiment.

\subsection{Metabolic indexes}

The relationship between the physiological rates and enzymatic activities showed a significant, positive correlation for the whole experiment (Supplementary Fig. A.4). Both $R \mathrm{O}_{2} / \mathrm{ETS}$ and $\mathrm{RNH}_{4}^{+} / \mathrm{GDH}$ ratios followed a similar trend over the three experimental phases (Fig. 4). Ratios in the low- and medium- $p \mathrm{CO}_{2}$ mesocosms revealed a high within-treatment variability and mean values of the same magnitude during oligotrophic conditions, while they were lower (significantly in the case of the $\mathrm{RO}_{2} / \mathrm{ETS}$ ) in the high- $p \mathrm{CO}_{2}$ treatment (Table 2). Following the phytoplankton bloom, the largest increase in the ratios was observed in mesozooplankton at medium- $p \mathrm{CO}_{2}$ levels, where the maximum average values for the entire experiment were registered, i.e. $\mathrm{RO}_{2}$ /ETS of $0.53 \pm 0.03$ and $\mathrm{RNH}_{4}^{+} / \mathrm{GDH}$ of $0.17 \pm 0.05$. Once the bloom decayed, the ratios decreased, except in the high- $p \mathrm{CO}_{2}$ mesocosms where the $\mathrm{RO}_{2}$ /ETS ratio remained the same and the $\mathrm{RNH}_{4}^{+} / \mathrm{GDH}$ ratio increased. Minimum values for the full experimental period were measured at medium- $p \mathrm{CO}_{2}$ levels on phase III for $R \mathrm{O}_{2} / \mathrm{ETS}$ $(0.24 \pm 0.08)$ and at high- $p \mathrm{CO}_{2}$ levels on phase II for $\mathrm{RNH}_{4}^{+} / \mathrm{GDH}$ $(0.08 \pm 0.01)$

We further calculated the $\mathrm{O} / \mathrm{N}$ ratio from the ETS and GDH measurements as a proxy for the organic compounds oxidized for energy (Fig. 5). In general, the metabolism of both micro- and mesozooplankton was based on the catabolism of proteins, as indicated by $\mathrm{O} / \mathrm{N}$ ratios below 7 . An exception was found during the bloom phase (phase effect, two-way ANOVA, Supplementary Table A.3), where microzooplankton showed increased values of $\mathrm{O} / \mathrm{N}$ at levels of $p \mathrm{CO}_{2}$ above $500 \mu \mathrm{atm}$, indicating a higher contribution of lipids to the total catabolism. Likewise, enhanced $\mathrm{O} / \mathrm{N}$ ratios were recorded in the two zooplankton size fractions in the low- $p \mathrm{CO}_{2}$ treatment during this phase, but corresponded only to the mesocosm M9, where the largest increase in the phytoplankton biomass occurred during the bloom (Taucher et al., 2018).

\section{4. $\mathrm{CO}_{2}$ effects on zooplankton metabolism under contrasting trophic conditions}

From the total of 48 linear regression analysis conducted to investigate potential $p \mathrm{CO}_{2}$ effects on the metabolic rates and indexes, only 14 were statistically significant $(p<0.05)$ and corresponded mainly to mesozooplankton (Tables 1 and 2). Microzooplankton did not show any significant effect of increased levels of $\mathrm{pCO}_{2}$ on the response variables (Table 1, Supplementary Table A.2), with the exception of the GDH activity during the bloom phase, which exhibited a negative relationship with $p \mathrm{CO}_{2}$ levels. As a consequence, the $\mathrm{O} / \mathrm{N}$ values in these mesocosms were significantly higher during this phase (phase and treatment interaction effect, two-way ANOVA, Supplementary Table A.2), indicating a more mixedbased metabolism in microzooplankton living at increasing $p \mathrm{CO}_{2}$ conditions.

Table 2 shows the correlations between $p \mathrm{CO}_{2}$ levels and response variables in mesozooplankton for the three experimental phases, while Supplementary Table A. 3 shows the variance of the response variables between phases and treatments. Biomass and enzymatic rates showed a significant 

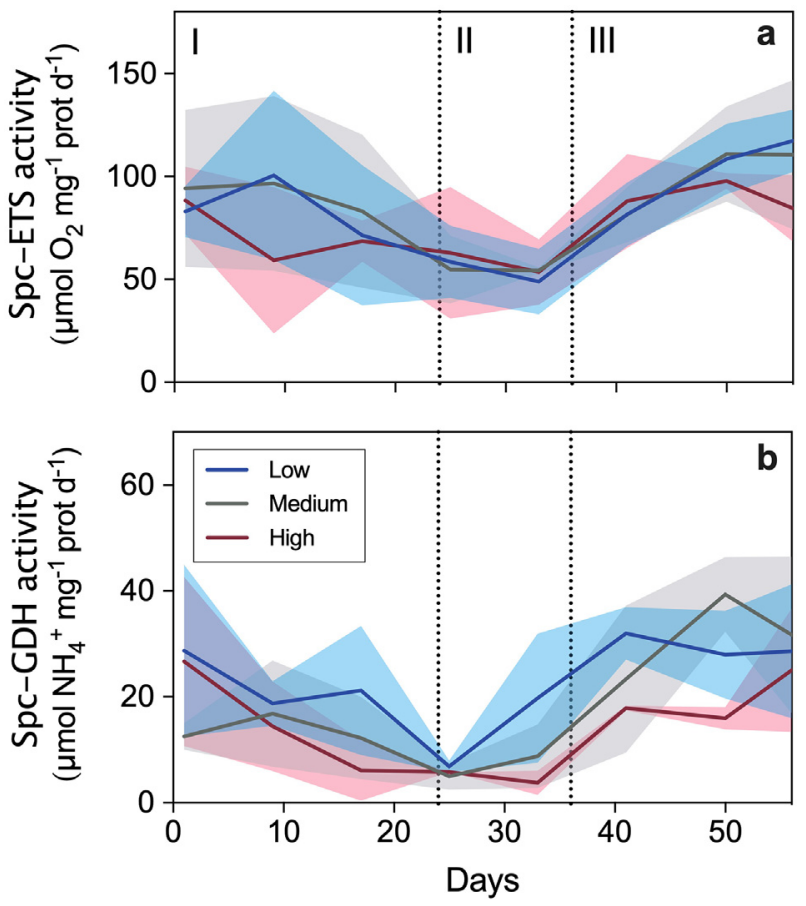

Fig. 3. Biomass-specific ETS (a) and GDH (b) activities in microzooplankton, averaged for the three $p \mathrm{CO}_{2}$ treatments. Light color shadows represent the standard deviation of the mean. Dotted vertical lines indicate the three phases during the experiment.

treatment effect during the experiment, with an interaction between the phases and treatments in the case of the enzymatic rates (Supplementary Table A.3). Thus, during oligotrophic conditions, biomass and enzymatic rates on a volume basis remained unaffected by $p \mathrm{CO}_{2}$, while biomassspecific physiological and enzymatic rates exhibited significant negative responses to increasing $p \mathrm{CO}_{2}$, except for the spc-ETS activity (Table 2). This lack of effect on spc-ETS activity can explain the observed significant relationship of $p \mathrm{CO}_{2}$ with both the $\mathrm{RO}_{2} / \mathrm{ETS}$ ratio (negative) and the $\mathrm{O} / \mathrm{N}$ ratio (positive) during this phase. Only proteinaceous biomass showed a significant negative correlation with $\mathrm{pCO}_{2}$ levels during bloom conditions. After the phytoplankton bloom, biomass and both enzymatic activities in the mesocosms presented a strong negative relationship with $p \mathrm{CO}_{2}$, while only biomass-specific rates related to respiration (spc-ETS and $\mathrm{RO}_{2}$ ) were significantly affected in a negative way (Supplementary Table A.3). We also observed a negative correlation between $p \mathrm{CO}_{2}$ and the $\mathrm{O} / \mathrm{N}$ ratio during the post-bloom phase.

\section{Discussion}

OA research has experienced an exponential increase over the last decade (Browman, 2016), with the majority of OA experiments following standard exposure scenarios according to the IPCC. However, it is increasingly more evident the importance of considering the habitat-specific natural range of $p \mathrm{CO}_{2}$ levels to correctly design OA studies and to correctly interpret the outcome of these investigations (Hofmann et al., 2011; Vargas et al., 2017). It may occur that studied organisms inhabit ecosystems that naturally exhibit $p \mathrm{CO}_{2}$ levels similar or even higher than those expected by the end of the century (Waldbusser and Salisbury, 2014), and hence their response would reflect the phenotypic plasticity of the evaluated traits rather than the potential effect of OA in the long-term (Vargas et al., 2017). In our study, we selected an averaged $\mathrm{pCO}_{2}$ gradient ranging from 350 to $1025 \mu \mathrm{atm}$ (Fig. 1, Supplementary Table A.1), which is well above the natural range of 320-420 $\mu$ atm reported for the surrounding waters off Gran Canaria (González-Dávila et al., 2010). Therefore, the metabolic responses determined in the medium- $\mathrm{pCO}_{2}(500-800 \mu \mathrm{atm})$ and high- $p \mathrm{CO}_{2}(800-1000 \mu \mathrm{atm})$ treatments reflect the potential OA effects on this subtropical zooplankton community under intermediate (RCP6.0) and high (RCP8.5) $\mathrm{CO}_{2}$ emission scenarios (IPCC, 2013), respectively.

This study includes the first information on the effect of OA on the key metabolic enzymes systems, ETS and GDH, that drive respiration and ammonium excretion in a zooplankton community. The two major highlights of our investigation are that, at the community level, (1) microzooplankton metabolism, as compared to mesozooplankton metabolism, was less affected by elevated $p \mathrm{CO}_{2}$ and, (2) OA-induced metabolic responses were distinct under nutrient-limiting conditions and after an upwelling-simulated phytoplankton bloom occurred (Fig. 1). Overall, the enzymatic ETS and GDH activities, as well as the $\mathrm{RO}_{2}$ and $\mathrm{RNH}_{4}^{+}$measured at ambient conditions (i.e. low treatment), were comparable to those reported previously for the same area and season (Fernández-Urruzola et al., 2016b; Osma et al., 2016a).
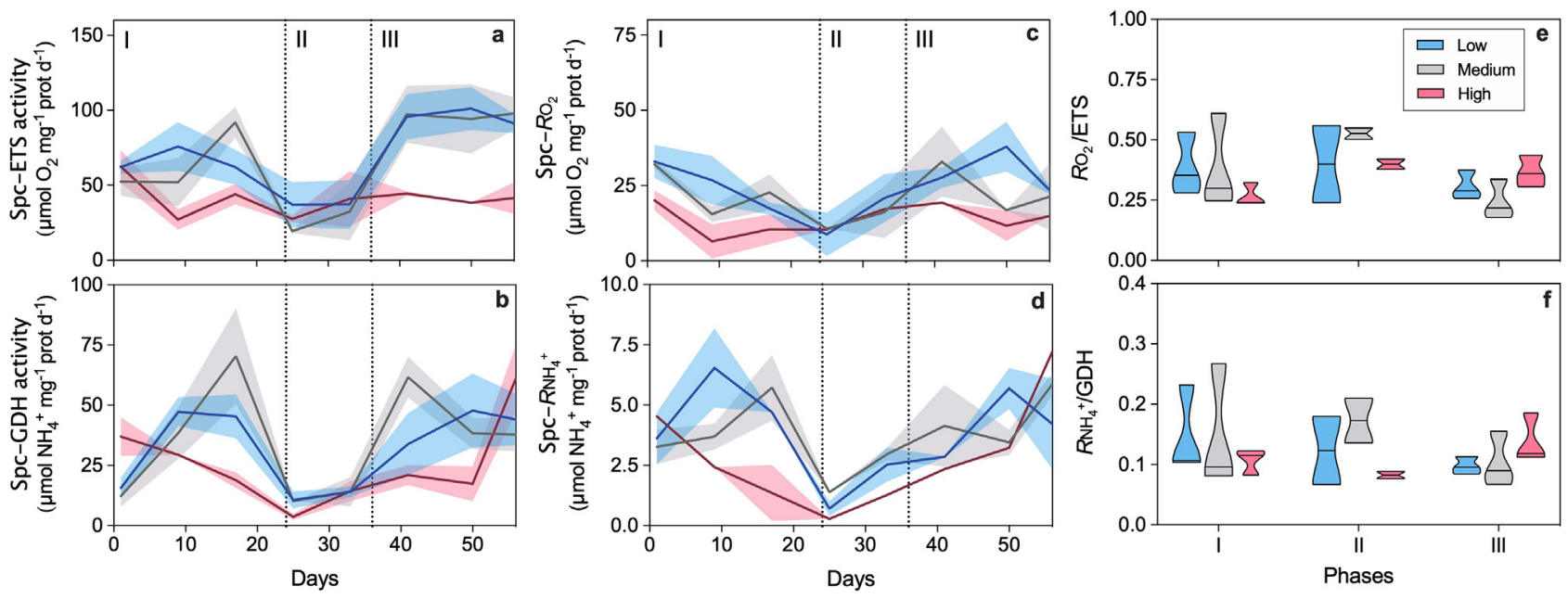

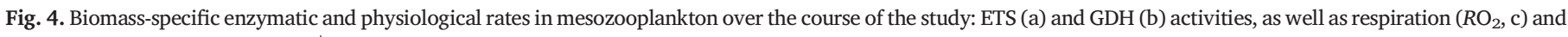

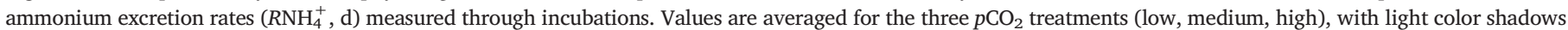

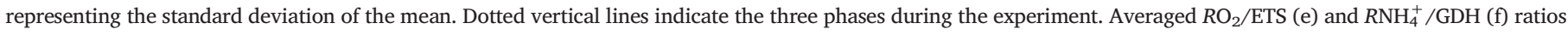

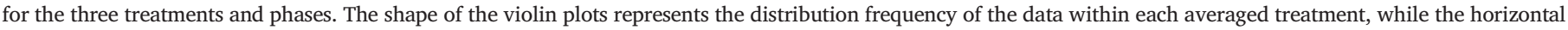
line stands for the mean. 

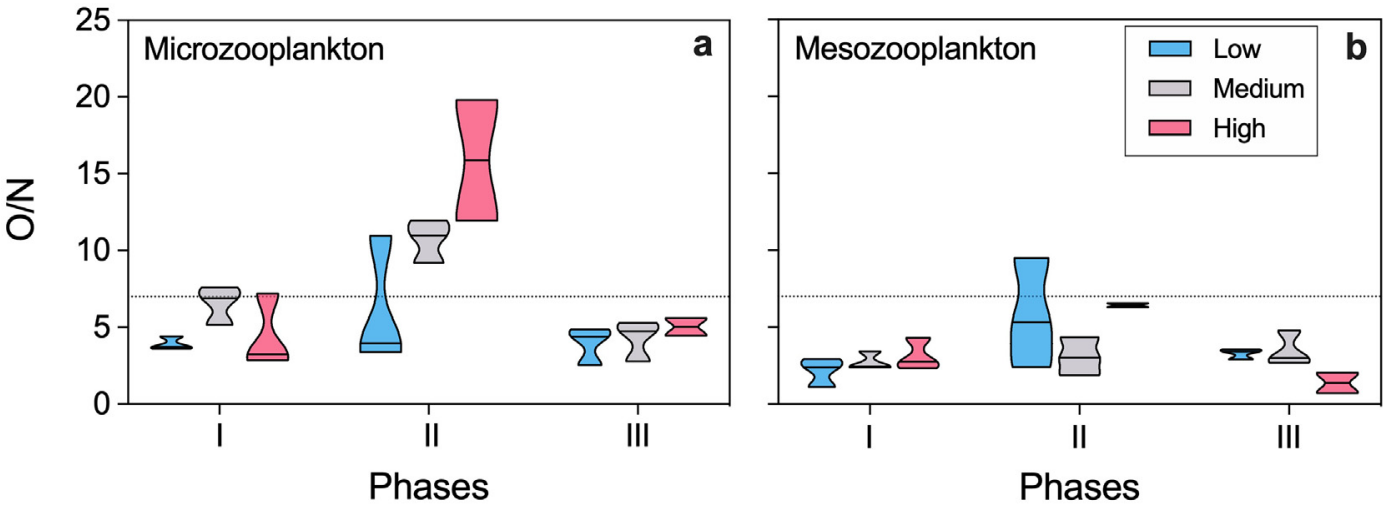

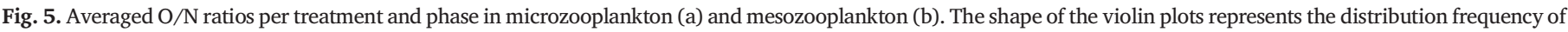

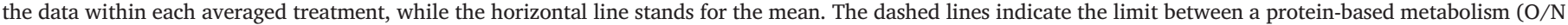
ratio $<7$ ) and a more mixed metabolism based on both protein and lipid catabolism (O/N ratio 7-24) (Mayzaud and Conover, 1988).

\subsection{OA-induced changes in zooplankton metabolism under oligotrophic condi- tions}

According to recent investigations (Bach et al., 2016; Paul et al., 2015; Sala et al., 2015), we expected to observe higher OA-induced negative impacts on the zooplankton metabolism during the oligotrophic conditions (phase I) of our experiment. Contrarily, during phase I microzooplankton proteinaceous biomass and enzymatic rates were unaffected by increased $p \mathrm{CO}_{2}$ levels (Table 1), with low and relatively constant values in all mesocosms (Fig. 2). The analysis of the zooplankton diversity and abundances in the same experiment showed that the microzooplankton community, dominated by aloricate ciliates and heterotrophic/mixotrophic dinoflagellates, did not evince a significant $p \mathrm{CO}_{2}$ effect during this phase (Algueró-Muñiz et al., 2019; Supplementary Fig. A.3, this study). Similarly, in phase I of the same mesocosm experiments, the microplankton $(<55 \mu \mathrm{m})$ ETS activity and proteinaceous biomass remained unaffected by increased $p \mathrm{CO}_{2}$ (TamesEspinosa et al., 2020). Taken together, these results suggest a certain degree of tolerance of this subtropical microzooplankton community toward OA under the prevailing nutrient-limiting conditions, as neither their abundance nor their key metabolic rates of respiration and ammonium excretion were affected by elevated $p \mathrm{CO}_{2}$. One could argue that this tolerance might be caused by an adjustment of microzooplankton metabolism over generations to increased $\mathrm{CO}_{2}$ levels. If this was the case, larger differences in the metabolic rates between treatments would have been expected at the beginning of the

Table 1

Statistical results from the linear regression analysis on response means to $p \mathrm{CO}_{2}$ over the respective phases for microzooplankton. The symbols indicate either a positive $(+)$ or a negative effect $(-)$ in the responses to increased $\mathrm{CO}_{2}$. Significant correlations $(p<0.05)$ are highlighted in bold.

\begin{tabular}{lllll}
\hline \multirow{2}{*}{ Biomass } & Phase & $p$ & $R^{2}$ & $F$ \\
& I & 0.747 & 0.016 & 0.113 \\
ETS & II & 0.599 & 0.049 & 0.308 \\
& III & 0.921 & 0.002 & 0.011 \\
& I & 0.357 & 0.122 & 0.972 \\
GDH & II & 0.566 & 0.058 & 0.368 \\
& III & 0.868 & 0.005 & 0.030 \\
Spc. ETS & I & 0.060 & 0.418 & 5.020 \\
& II & $\mathbf{0 . 0 3 3}(-)$ & $\mathbf{0 . 5 5 9}$ & $\mathbf{7 . 6 1 4}$ \\
& III & 0.458 & 0.095 & 0.628 \\
Spc. GDH & I & 0.339 & 0.131 & 1.051 \\
& II & 0.361 & 0.140 & 0.976 \\
O/N & III & 0.294 & 0.180 & 1.320 \\
& I & 0.671 & 0.027 & 0.197 \\
& II & 0.121 & 0.352 & 3.257 \\
& III & 0.555 & 0.061 & 0.391 \\
& I & 0.777 & 0.004 & 0.083 \\
& II & $\mathbf{0 . 0 2 3}(+)$ & $\mathbf{0 . 4 5 5}$ & $\mathbf{7 . 5 1 1}$ \\
& III & 0.354 & 0.039 & 0.898 \\
\hline
\end{tabular}

experiment, when no effective adjustment has probably yet occurred, to then decrease as the experiment progressed. However, as observed in Fig. 2, the metabolic rates and biomass in microzooplankton were not significantly different between treatments at the beginning of this period, suggesting that direct $p \mathrm{CO}_{2}$ effects were minor and that they most likely did not imply a significant intergenerational adjustment of the enzymatic rates and biomass to face increased $\mathrm{CO}_{2}$ levels. This allows us to compare the $\mathrm{CO}_{2}$ effects on the two zooplankton size-classes considered in this study, regardless the typical differences in their generation times.

Mesozooplankton showed a higher OA-impact on their metabolism during this phase, as most of the biomass-specific response traits decreased with increasing $p \mathrm{CO}_{2}$ (Fig. 4, Table 2). While these traits remained high or even increased at the low- and medium $p \mathrm{CO}_{2}$ treatments during this phase, they decreased with the high- $p \mathrm{CO}_{2}$ treatment. One potential

Table 2

Statistical results from the linear regression analysis on response means to $p \mathrm{CO}_{2}$ over the respective phases for mesozooplankton. The symbols indicate either a positive $(+)$ or a negative effect $(-)$ in the responses to increased $\mathrm{CO}_{2}$. Significant correlations $(\mathrm{p}<0.05)$ are highlighted in bold.

\begin{tabular}{|c|c|c|c|c|}
\hline & Phase & $p$ & $R^{2}$ & $F$ \\
\hline \multirow[t]{3}{*}{ Biomass } & I & 0.668 & 0.028 & 0.20 \\
\hline & II & $0.018(-)$ & 0.632 & 10.29 \\
\hline & III & $0.003(-)$ & 0.794 & 23.07 \\
\hline \multirow[t]{3}{*}{ ETS } & I & 0.789 & 0.011 & 0.08 \\
\hline & II & 0.076 & 0.433 & 4.57 \\
\hline & III & $0.012(-)$ & 0.679 & 12.71 \\
\hline \multirow[t]{3}{*}{ GDH } & I & 0.406 & 0.101 & 0.78 \\
\hline & II & 0.083 & 0.420 & 4.34 \\
\hline & III & $0.002(-)$ & 0.809 & 25.38 \\
\hline \multirow[t]{3}{*}{ Spc. ETS } & I & 0.931 & 0.001 & 0.00 \\
\hline & II & 0.871 & 0.005 & 0.03 \\
\hline & III & $0.030(-)$ & 0.572 & 8.00 \\
\hline \multirow[t]{3}{*}{ Spc. GDH } & I & $0.042(-)$ & 0.468 & 6.17 \\
\hline & II & 0.890 & 0.003 & 0.02 \\
\hline & III & 0.206 & 0.251 & 2.01 \\
\hline \multirow[t]{3}{*}{ Spc. $\mathrm{R}_{\mathrm{O} 2}$} & I & $0.007(-)$ & 0.666 & 13.97 \\
\hline & II & 0.182 & 0.395 & 2.61 \\
\hline & III & $0.049(-)$ & 0.334 & 5.022 \\
\hline \multirow[t]{3}{*}{ Spc. $\mathrm{R}_{N H 4}$} & I & $0.022(-)$ & 0.610 & 9.39 \\
\hline & II & 0.096 & 0.540 & 4.70 \\
\hline & III & 0.206 & 0.251 & 2.01 \\
\hline \multirow[t]{3}{*}{$\mathrm{R}_{\mathrm{O} 2} / \mathrm{ETS}$} & I & $0.031(-)$ & 0.638 & 8.83 \\
\hline & II & 0.704 & 0.040 & 0.17 \\
\hline & III & 0.400 & 0.103 & 0.80 \\
\hline \multirow[t]{3}{*}{$\mathrm{R}_{\mathrm{NH}_{4}} / \mathrm{GDH}$} & I & 0.195 & 0.262 & 2.13 \\
\hline & II & 0.267 & 0.294 & 1.66 \\
\hline & III & 0.516 & 0.063 & 0.47 \\
\hline \multirow[t]{3}{*}{$\mathrm{O} / \mathrm{N}$} & I & $0.049(+)$ & 0.445 & 5.61 \\
\hline & II & 0.684 & 0.030 & 0.18 \\
\hline & III & $0.048(-)$ & 0.505 & 6.12 \\
\hline
\end{tabular}


explanation for this decrease might be an OA-associated change in the mesozooplankton community composition and/or in the populations size structure (i.e. relative contribution of different developmental stages), which might have led to a community dominated by organisms with lower biomass-specific rates. However, according to the community structure analysis (Algueró-Muñiz et al., 2019; Supplementary Fig. A.3, this study), this was not the case since the mesozooplankton community composition and abundances remained unaffected by increased $p \mathrm{CO}_{2}$ during this phase. Mesozooplankton was largely dominated by copepods throughout this experiment ( $\sim 90 \%$ ), and only showed significant $p \mathrm{CO}_{2}$-related abundance shifts during the post-bloom phase (Algueró-Muñiz et al., 2019; Supplementary Fig. A.3, this study). Another explanation for the observed OAinduced decrease in the metabolic rates might be a direct effect of $\mathrm{CO}_{2}$ concentration on the mechanisms involved on the respiratory and excretory processes of mesozooplankton. Previous research evaluating the direct effects of increased $p \mathrm{CO}_{2}$ on the metabolism of marine crustaceans have typically reported increased respiration (Isari et al., 2015; Li and Gao, 2012; Wang et al., 2018) and ammonium excretion rates (Saba et al., 2012). These increases were attributed to enhanced metabolic costs. Depending on the species, zooplankton is more or less capable of modulating the intracellular acid-base balance through energy-consuming regulatory processes to counteract external $\mathrm{pH}$ changes. This increased cost of homeostasis can be met through increased food intake (compensatory feeding) (Li and Gao, 2012; Wang et al., 2018). This mechanism is usually studied under laboratory-controlled conditions, where organisms are provided with an excess of food. But, when food availability is a limiting factor, the supply of energy is restricted and the damaging effects of high $\mathrm{CO}_{2}$ may not be compensated (Pedersen et al., 2014). In this case, the zooplankton can adopt a metabolic suppression strategy that acts as a short-term solution to the acid-base imbalance (Todgham and Hofmann, 2009; Cripps et al., 2016). One might assume that, during the oligotrophic conditions of our experiments, the mesozooplankton experienced food-deprivation since the abundances of large phytoplankton and microzooplankton were low (Algueró-Muñiz et al., 2019; Taucher et al., 2018; Supplementary Figs. A.2 and A.3, this study). However, in order to address this possibility, dedicated experiments addressing the OA impact on the grazing rates of this mesozooplankton community would be required. An indirect effect of OA on the food quality for mesozooplankton may have likewise caused the metabolic decrease observed during this phase. Increased $p \mathrm{CO}_{2}$ levels have been observed to alter the elemental composition of phytoplankton communities (Riebesell et al., 2007) as well as the phytoplankton speciesspecific biochemical composition (i.e. lipid:protein:carbohydrate ratios) (Cripps et al., 2016). This impact can travel up the food web affecting zooplankton and higher trophic levels (Malzahn et al., 2007). In the current study, we have calculated the $\mathrm{O} / \mathrm{N}$ ratio as a proxy to evaluate the metabolic compound oxidized for energy (Mayzaud and Conover, 1988) (Fig. 5). Although the values reflected a predominant protein-based metabolism during oligotrophic conditions, we observed a significant increase of the $\mathrm{O} / \mathrm{N}$ ratio in mesozooplankton with increasing $\mathrm{CO}_{2}$ (Table 2). This is attributed to the distinct responsiveness of spc-ETS and spc-GDH activities to $p \mathrm{CO}_{2}$ levels (Fig. 4). Whether this different impact of elevated $\mathrm{CO}_{2}$ on these enzymes is caused by different sensitivities to hypercapnia in the cells or to biochemical adjustments induced by changes in the food quality needs further investigation. Our experimental set up does not allow us to differentiate between these direct and indirect OA effects on mesozooplankton metabolism. Nevertheless, the combined interaction of all these effects, which resembles a natural scenario, has revealed that predicted $p \mathrm{CO}_{2}$ levels by the end of the century (RCP8.5) could cause an overall down-regulation of the metabolic rates of this subtropical zooplankton community under the prevailing oligotrophic conditions in the area, with the subsequent biogeochemical implications.

\subsection{OA-induced changes in zooplankton metabolism after a simulated upwelling}

Considering that food availability can counteract the negative effect of increasing OA, we expected to observe either neutral or positive effects of increasing $\mathrm{pCO}_{2}$ on the zooplankton metabolic rates during the bloom and post-bloom phase. Contrarily, high $p \mathrm{CO}_{2}$ levels, in general, negatively affected the metabolism of the zooplankton community in the last two phases of the experiment (Fig. 2), which we associate with the presence of the toxic algae in these mesocosms (V.globosus). After the deep water addition (Taucher et al., 2018), a phytoplankton bloom of large, chainforming diatoms peaked in all mesocosms, but at the high- $\mathrm{pCO}_{2}$ conditions, this nutrient-rich seawater fertilization further triggered the proliferation of the toxic V. globosus to form a HAB (Fig. 1; Riebesell et al., 2018). V. globosus produces haemolytic cytotoxins, which impair membrane permeability and lead to osmotic cell lysis (Chang, 2015). Furthermore, this alga, under elevated $p \mathrm{CO}_{2}$ conditions, caused a drop in the zooplankton abundance to prebloom levels and a delay in the temporal development of the zooplankton community (Algueró-Muñiz et al., 2019; Riebesell et al., 2018; Supplementary Fig. A.3, this study). In accordance with these observations, here we also report a strong impact on the zooplankton metabolic rates. In addition to the impact of the HAB presence, another factor that may have contributed to some extent to the decrease on these rates is the dominance of the diatom Guinardia striata under this high- $p \mathrm{CO}_{2}$ conditions (Taucher et al., 2018), which may be too large to be grazed by zooplankton.

Microzooplankton biomass and enzymatic activities increased after the phytoplankton bloom at high $\mathrm{CO}_{2}$ levels although this increase was delayed and was of lower magnitude (especially in the GDH), as compared to the low and medium $p \mathrm{CO}_{2}$ treatments (Fig. 2). The significant impact on the GDH led to a shift in the metabolic compounds used for energy during phase II, as the microzooplankton changed from a protein-based diet to a more mixed one, including lipids (Fig. 5). Whether this shift in the metabolism was caused by an OA-induced change in the food quality for microzooplankton (Cripps et al., 2016) or by an increased use of lipid reserves to face metabolic stress derived from hypercapnia (Engström-Öst et al., 2020) and/or to the presence of the cytotoxin cannot be determined with the available data.

Mesozooplankton metabolism was even more profoundly affected by the presence of $V$. globosus (Fig. 2). When this microalga reached HAB levels, the biomass, enzymatic activities and physiological rates in the mesozooplankton decreased to pre-bloom values, suggesting a metabolic suppression during the time they were exposed to the cytotoxin. After the microalga abundance in the mesocosms dropped, the GDH and $\mathrm{RNH}_{4}^{+}$ started to increase while the ETS and $\mathrm{RO}_{2}$ remained low until the end of the experiment. We attribute this different effect on the respiratory and excretory metabolism as related to a difference in the chemical reaction of the cytotoxin with the two different metabolic enzymes systems. The ETS is composed of four-enzymatic complexes embedded in the mitochondrial internal membrane in eukaryotic organisms. Electrons are transported through these complexes up to a last complex (cytochrome oxidase) where oxygen is reduced to water. During the transport of these electrons, a membrane potential is created that drives energy transformation, resulting in the production of ATP. As described by Chang (2015), the haemolytic cytotoxin of $V$. globosus affects the permeability of the membranes and hence, it can disrupt the transport of electrons between the different components of the ETS as well as the ATP production. This subsequent drop in ATP formation, would lead to metabolic suppression, a drop in measured ETS activity. Why the two zooplankton size fractions exhibit different responses to the presence of the toxic alga is not clear. Experimentation on dedicated culture are required to test sensitivities of the different functional groups and life stages (in case of copepods), to the $V$. globosus's cytotoxin. Altogether, our results show that OA-induced HAB presence in subtropical waters will have strong impact in the metabolism of marine zooplankton.

\subsection{OA effect on metabolic indexes}

Since they were first introduced, the enzymatic assays of ETS and GDH have been frequently used as proxies for respiration and ammonium excretion in specific components of marine ecosystems, ranging from bacteria to fishes (Belcher et al., 2020; Finlay et al., 1983; Osma et al., 2016c; RomeroKutzner et al., 2015; Fernández-Urruzola et al., 2011). These potential rates 
are usually converted into actual rates by means of empirically determined $\mathrm{RO}_{2} / \mathrm{ETS}$ and $\mathrm{RNH}_{4}^{+} / \mathrm{GDH}$ ratios. However, factors such as body size, food quantity and quality can affect the physiology and enzymatic activities at different time scales (Berges et al., 1993; Fernández-Urruzola et al., 2016a; Osma et al., 2016b), thereby causing variability in the ratios and precluding the use of single universal values. Here, we aimed to evaluate, for the first time, if the $p \mathrm{CO}_{2}$ level is an additional factor causing variability in these ratios in marine zooplankton. Our results revealed that the physiological rates and enzymatic activities are affected to the same extent by increased $p \mathrm{CO}_{2}$ or, in other words, that the $\mathrm{RO}_{2} / \mathrm{ETS}$ and $\mathrm{RNH}_{4}^{+} / \mathrm{GDH}$ ratios are generally unaffected by the OA conditions expected by the end of the century. This is in agreement with recent results in microplankton (Filella et al., 2018). We observed one exception to this trend in mesozooplankton during oligotrophic conditions, which showed a significant negative effect on the $\mathrm{RO}_{2}$ /ETS ratio (Table 2). This is likely associated to the constitutive nature of the ETS and a strategy of cells to short-term fluctuations of a stressor. It has been observed before that under food-shortage (nutrient limitation), conditions that we most probably had during the oligotrophic phase, the response of the ETS is more attenuated as compared to the $\mathrm{RO}_{2}$ (Osma et al., 2016c), as a strategy to make use of resources once they are available again.

\subsection{Biogeochemical implications of $O A$ effects on zooplankton metabolism}

Zooplankton play a significant role through their metabolism on the remineralization of the organic matter and on the nutrient regeneration. These two processes have direct impacts on primary production and the magnitude and efficiency of the biological carbon pump. At a global scale, their respiratory carbon demands may account for $14-25 \%$ of photosynthetically-fixed carbon in the surface waters (Hernández-León et al., 2008). During the transformation of the particulate organic matter into the dissolved pools, there is a release of inorganic nutrient salts into seawater that results from catabolic pathways and that primary producers utilize for biomass production. Ammonium excretion is responsible for the largest source of recycled nitrogen in the euphotic zone (Bronk and Steinberg, 2008) and zooplankton, specifically, contribute through this process between 12 and $23 \%$ to the primary production (Hernández-León et al., 2008). All these percentages depend on several factors such as the primary productivity in seawater, the community structure, and the effect of environmental factors on metabolic rates. Here, we discuss the impact that zooplankton have on the primary production under the three scenarios considered in this study (Fig. 6): (1) ambient $p \mathrm{CO}_{2}$ levels and oligotrophic conditions, (2) future $p \mathrm{CO}_{2}$ levels and oligotrophic conditions, and (3) future $p \mathrm{CO}_{2}$ conditions and enhanced influence of upwelled waters, with the presence of a $\mathrm{HAB}$.

During the oligotrophic phase of our experiment, the low nutrient concentrations resulted in a low and stable total primary productivity (PP) in the mesocosms, ranging between 2 and $10 \mathrm{mmol} \mathrm{C} \mathrm{m}^{-3} \mathrm{~d}^{-1}$, as shown by Hernández-Hernández et al. (2018). These authors further reported no significant $p \mathrm{CO}_{2}$ effects on the PP under these conditions. Our estimates of oxygen consumption during this phase ranged between 0.11-0.25 $\mathrm{mmol} \mathrm{O}_{2} \mathrm{~m}^{-3} \mathrm{~d}^{-1}$ and 0.07-0.20 $\mathrm{mmol} \mathrm{O}_{2} \mathrm{~m}^{-3} \mathrm{~d}^{-1}$ at ambient and high $p \mathrm{CO}_{2}$ levels, respectively. Assuming a respiratory quotient of 0.86 (Omori and Ikeda, 1984), the zooplankton respiratory carbon demands could potentially account for $2.2-4.8 \%$ of PP at present conditions and $1.7-2.9 \%$ of PP at projected high $p \mathrm{CO}_{2}$ levels (Fig. 6). It should be noted that these percentages consider (1) respiratory carbon losses and not ingestion or grazing rates and, (2) microzooplankton larger than $55 \mu \mathrm{m}$. This implies that the metabolic demands of small dinoflagellates and ciliates, which are considered the major remineralizers together with the bacterial community (Calbet and Landry, 2004) are not included in the calculations. Overall, our estimates reveal that, on average, the contribution of zooplankton to the remineralization of the PP in oligotrophic systems may decrease by about one third due to OA. Similarly, the range of zooplankton contribution to the regenerated PP through ammonium excretion (considering a C/ $\mathrm{N}$ uptake ratio by phytoplankton of 6.1; Dugdale and Goering, 1967) may drop from $6.7-14.3 \%$ (present conditions) to $4.5-11.4 \%$ (high $\mathrm{pCO}_{2}$ conditions) in this system, an average decrease of $24 \%$ under the projected OA scenario. Thus, this OA impact on the zooplankton metabolism might have potential implications for the organic-matter turnover and for the characteristics of the sinking material. In this regard, a recent study by Taucher et al. (2020) evaluated the influence of OA on changes in the C/ $\mathrm{N}$ ratios of organic matter during sinking $(\Delta \mathrm{C} / \mathrm{N}$, Fig. 6) in several mesocosm experiments conducted at different locations, including ours. They reported an increase in the $\mathrm{C} / \mathrm{N}$ ratios of the sinking material with increasing $p \mathrm{CO}_{2}$ during the oligotrophic phase, which they attributed to

Low $\mathrm{pCO}_{2}$ levels (present)

Oligotrophic conditions

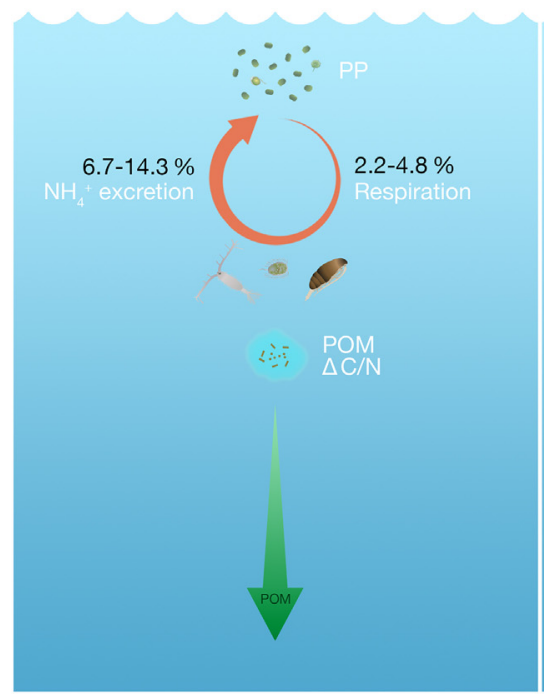

Oligotrophic conditions

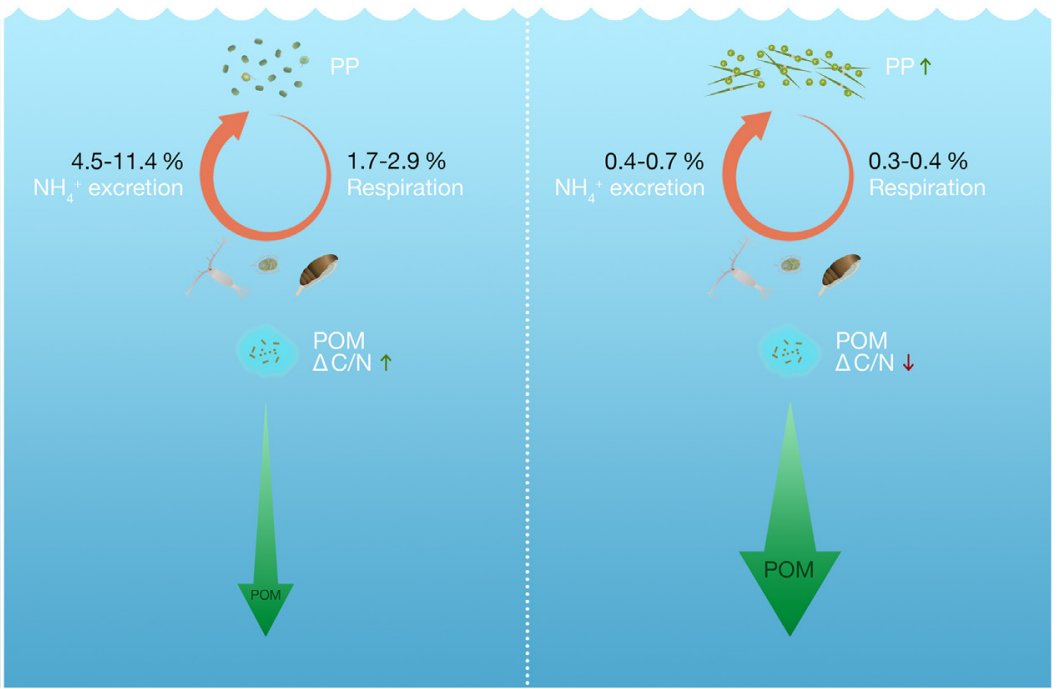

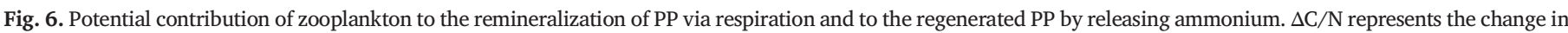

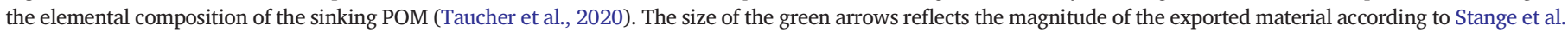

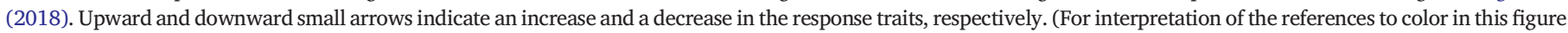
legend, the reader is referred to the web version of this article.) 
enhanced degradation processes by heterotrophic organisms (from bacteria to zooplankton), with preferential $\mathrm{N}$ remineralization. Our results in zooplankton suggest that the comparatively larger effect of OA on the respiratory carbon consumption than on the $\mathrm{NH}_{4}^{+}$production process (i.e. a decline of $33 \pm 15 \%$ vs $24 \pm 12 \%$ ) may have likewise contributed to a certain extent to the increase in the $\mathrm{C} / \mathrm{N}$ ratios observed by these authors.

According to the "Upwelling Intensification Hypothesis" introduced by Bakun (1990), global warming may ultimately result in an intensification of coastal upwelling, increasing the influence of nutrient-rich waters in nearby oligotrophic systems through mesoscale processes. The simulation of such a nutrient fertilization event during the experiment gave rise to a 15 -fold increase in the PP, reaching values between 30 and $70 \mathrm{mmol} \mathrm{C} \mathrm{m}^{-3} \mathrm{~d}^{-1}$ (Hernández-Hernández et al., 2018). The zooplankton respiration and ammonium excretion responded rapidly to this increased food availability at ambient conditions (low $p \mathrm{CO}_{2}$ ) but to a lesser extent than did the PP (4-5-fold increase) (Fig. 2). At high $p \mathrm{CO}_{2}$ conditions, however, the $\mathrm{HAB}$ of $V$. globosus developed after the nutrient fertilization caused a profound effect on the zooplankton metabolism, leading to a significant decrease in their relative impact on the PP. Thus, the respiratory carbon demands of zooplankton were equivalent to only $0.3-0.4 \%$ of PP and the zooplankton contribution to regenerated PP declined to $0.4-0.7 \%$ (Fig. 6). This corresponds to an OA-associated decrease of up to $70 \%$ with respect to ambient $p \mathrm{CO}_{2}$ levels under these simulated upwelling conditions. The metabolic suppression in zooplankton caused by the presence of the toxic alga may have had additional consequences in the dynamics and the elemental composition of the particulate organic matter in the water column. A parallel study conducted during the same experiment showed that, even though the sedimentation rates were higher than during oligotrophic conditions in all mesocosms after the deep-water addition, these rates were comparatively lower in the high $\mathrm{CO}_{2}$ treatment (Stange et al., 2018). Additionally, the comparison of the $\mathrm{C} / \mathrm{N}$ values in the exported material with the $\mathrm{C} / \mathrm{N}$ of the particulate organic matter $(\mathrm{POM})$ in the water column $(\Delta \mathrm{C} / \mathrm{N})$ revealed that the $\mathrm{C} / \mathrm{N}$ in the sinking material decreased with increasing $\mathrm{pCO}_{2}$ (Taucher et al., 2020). These authors further observed that a larger portion of POM remained suspended in the water column and did not sink at high $p \mathrm{CO}_{2}$ conditions, which they attribute to a lower grazing and packaging of POM into faster sinking particles by zooplankton. Their findings may be likewise explained to some extent by the more attenuated remineralization rates that we found during these phases, likely associated to an indirect effect of OA caused by the strong negative impact of V. globosus on the zooplankton community.

All in all, our results show that projected OA conditions by the end of the century may have a significant impact in the metabolic rates of this subtropical zooplankton community, especially in the larger size fraction, either through direct effects on their physiology or through indirect effects caused by the eventual presence of harmful algae at high-nutrients conditions. Given the role that these organisms play in the mineralization of organic matter and in the nutrient cycling through their metabolism, this could have potential implications in the carbon and nitrogen cycles of oligotrophic systems, one of the larger ecosystems on Earth.

\section{CRediT authorship contribution statement}

Natalia Osma: Conceptualization, Funding acquisition, Data curation, Formal analysis, Investigation, Resources, Visualization, Writing - original draft, Writing - review \& editing. Cristian A. Vargas: Visualization, Writing - review \& editing. María Algueró-Muñíz: Data curation, Investigation. Lennart T. Bach: Data curation, Investigation, Writing - review \& editing. May Gómez: Conceptualization, Resources, Writing - review \& editing. Henriette G. Horn: Data curation, Investigation. Andrea Ludwig: Data curation, Project administration, Resources, Supervision. Theodore T. Packard: Conceptualization, Resources, Writing - review \& editing. Ulf Riebesell: Conceptualization, Funding acquisition, Investigation, Project administration, Resources, Supervision, Validation, Writing - review \& editing. Vanesa Romero-Kutzner: Investigation, Writing - review \& editing. Jan Taucher: Data curation, Investigation, Writing - review \& editing. Igor Fernández-Urruzola: Conceptualization, Funding acquisition, Data curation, Formal analysis, Investigation, Resources, Visualization, Writing - original draft, Writing - review \& editing.

\section{Declaration of competing interest}

The authors declare that they have no known competing financial interests or personal relationships that could have appeared to influence the work reported in this paper.

\section{Acknowledgements}

We thank the Plataforma Oceánica de Canarias (PLOCAN) for hosting and supporting us during these experiments. We are also grateful to the captain and crew of RV Hespérides for deploying and recovering the mesocosms (cruise 29HE20140924), as well as RV Poseidon for transporting the mesocosms and the support in testing the deep-water collector (cruise POS463). We are grateful to "The Gran Canaria KOSMOS Consortium" for all the help and support received during on-site work. N.O., I. F.-U. and C.A.V. also acknowledge support from the Millennium Science Initiative from Chile's Ministry of Economy, Development and Tourism through the Millennium Institute of Oceanography (IMO), MINECON IC120019.

The German Federal Ministry of Education and Research (BMBF) funded this project in the framework of the coordinated project BIOACIDBiological Impacts of Ocean Acidification, phase 2 (FKZ 03F06550). N.O., I. F.-U. and C.A.V. received financial support from FONDECYT (ANID) research programs 3190365, 3180352 and 1170065, respectively, during the writing process. U.R. received additional funding from the Leibniz Award 2012 by the German Research Foundation (DFG).

\section{Appendix A. Supplementary data}

Supplementary data to this article can be found online at https://doi. org/10.1016/j.scitotenv.2021.152252.

\section{References}

Aberle, N., et al., 2013. High tolerance of microzooplankton to ocean acidification in an Arctic coastal plankton community. Biogeosciences 10, 1471-1481.

Algueró-Muñiz, M., et al., 2017. Ocean acidification effects on mesozooplankton community development: results from a long-term mesocosm experiment. PLoS ONE 12, 1-21. https://doi.org/10.1371/journal.pone.0175851.

Algueró-Muñiz, M., et al., 2019. Analyzing the impacts of elevated-CO2 levels on the development of a subtropical zooplankton community during oligotrophic conditions and simulated upwelling. Front. Mar. Sci. 6.

Arístegui, J., Hernández-León, S., Montero, M.F., Gómez, M., 2001. The seasonal planktonic cycle in coastal waters of the Canary Islands. Sci. Mar. 65, 51-58.

Bach, L.T., et al., 2016. Influence of ocean acidification on a natural winter-to-summer plankton succession: first insights from a long-term mesocosm study draw attention to periods of low nutrient concentrations. PLoS ONE 11, 1-33. https://doi.org/10.1371/journal. pone. 0159068

Bakun, A., 1990. Global climate change and intensification of coastal ocean upwelling. Science 247, 198-201. https://doi.org/10.1126/science.247.4939.198.

Belcher, A., et al., 2020. Respiration of mesopelagic fish: a comparison of respiratory electron transport system (ETS) measurements and allometrically calculated rates in the Southern Ocean and Benguela current. ICES J. Mar. Sci. 77, 1672-1684.

Berges, J.A., Roff, J.C., Ballantyne, J.S., 1993. Enzymatic indices of respiration and ammonia excretion: relationships to body size and food levels. J. Plankton Res. 15, 239-254.

Bidigare, R.R., King, F.D., 1981. The measurement of glutamate dehydrogenase activity in Praunus flexuosus and its role in the regulation of ammonium excretion. Comp. Biochem. Physiol. 70, 409-413.

Bronk, D.A., Steinberg, D.K., 2008. Nitrogen regeneration. In: Carpenter, E.J., Capone, D.G. (Eds.), Nitrogen in the Marine Environment. Academic Press, London, pp. 385-467.

Browman, H.I., 2016. Applying organized scepticism to ocean acidification research. ICES J. Mar. Sci. 73, 529-536

Calbet, A., Landry, M.R., 2004. Phytoplankton growth, microzooplankton grazing, and carbon cycling in marine systems. Limnol. Oceanogr. 49, 51-57.

Caldeira, K., Wickett, M.E., 2003. Anthropogenic carbon and ocean pH. Nature 425, 365.

Chang, F., 2015. Cytotoxic effects of vicicitus globosus (Class Dictyochophyceae) and chattonella marina (Class raphido- phyceae) on rotifers and other microalgae. J. Mar. Sci. Eng. 3, 401-411.

Cripps, G., Flynn, K.J., Lindeque, P.K., 2016. Ocean acidification affects the phyto-zoo plankton trophic transfer efficiency. PLoS ONE 11 e0151739-15. 
Dugdale, R.C., Goering, J.J., 1967. Uptake of new and regenerated forms of nitrogen in primary productivity. Limnol. Oceanogr. 12, 196-206.

Engström-Öst, J., et al., 2020. Oxidative stress and antioxidant defence responses in two marine copepods in a high CO2 experiment. Sci. Total Environ. 745, 140600.

Fernández-Urruzola, I., Packard, T.T., Gómez, M., 2011. GDH activity and ammonium excretion in the marine mysid, Leptomysis lingvura: effects of age and starvation. J. Exp. Mar. Biol. Ecol. 409, 21-29. https://doi.org/10.1016/j.jembe.2011.07.035.

Fernández-Urruzola, I., Osma, N., Packard, T., Gómez, M., Postel, L., 2014. Distribution of zooplankton biomass and potential metabolic activities across the northern Benguela upwelling system. J. Mar. Syst. 140, 138-149. https://doi.org/10.1016/j.jmarsys.2014.05. 009.

Fernández-Urruzola, I., Osma, N., Gómez, M., Montesdeoca-Esponda, S., Packard, T.T., 2016a. Building a model of ammonium excretion in two species of marine zooplankton based on glutamate dehydrogenase kinetics. Mar. Ecol. Prog. Ser. 550, 83-99.

Fernández-Urruzola, I., Osma, N., Packard, T., Maldonado, F., Gómez, M., 2016b. Spatiotemporal variability in the GDH activity to ammonium excretion ratio in epipelagic marine zooplankton. Deep-Sea Res. I Oceanogr. Res. Pap. 117, 61-69. https://doi.org/10. 1016/j.dsr.2016.09.005.

Filella, A., et al., 2018. Plankton community respiration and ETS activity under variable CO2 and nutrient fertilization during a mesocosm study in the subtropical North Atlantic. Front. Mar. Sci. 5 1563-11.

Finlay, B.J., Span, A., Ochsenbein-Gattlen, C., 1983. Influence of physiological state on indices of respiration rate in protozoa. Comp. Biochem. Physiol. 74, 211-219.

Gattuso, J.-P., Hansson, L., 2011. Ocean acidification: background and history. Ocean Acidification. Oxford University Press, pp. 1-20 https://doi.org/10.1093/oso/9780199591091. 003.0006 .

González-Dávila, M., Santana-Casiano, J.M., Rueda, M.J., Llinás, O., 2010. The water column distribution of carbonate system variables at the ESTOC site from 1995 to 2004. Biogeosciences 7, 3067-3081.

Hernández-Hernández, N., et al., 2018. High CO2 under nutrient fertilization increases primary production and biomass in subtropical phytoplankton communities: a mesocosm approach. Front. Mar. Sci. 5 95-14.

Hernández-León, S., Fraga, C., Ikeda, T., 2008. A global estimation of mesozooplankton ammonium excretion in the open ocean. J. Plankton Res. 30, 577-585.

Hofmann, G.E., et al., 2011. High-frequency dynamics of ocean ph: a multi-ecosystem comparison. PLOS ONE 6, 1-11. https://doi.org/10.1371/journal.pone.0028983.

IPCC, 2013. Climate change 2013: the physical science basis. In: Stocker, T.F., Qin, D., Plattner, G.-K., Tignor, M., Allen, S.K., Boschung, J. (Eds.), Contribution of Working Group I to the Fifth Assessment Report of the Intergovernmental Panel on Climate Change. Cambridge University Press, Cambridge.

Isari, S., Zervoudaki, S., Saiz, E., Pelejero, C., Peters, J., 2015. Copepod vital rates under CO2induced acidification: a calanoid species and a cyclopoid species under short-term exposures. J. Plankton Res. 47, 912-922.

Kroeker, K.J., et al., 2013. Impacts of ocean acidification on marine organisms: quantifying sensitivities and interaction with warming. Glob. Chang. Biol. 19, 1884-1896. https:// doi.org/10.1111/gcb.12179.

Le Quéré, C., et al., 2016. Global carbon budget 2016. Earth Syst. Sci. Data 8, 605-649. https://doi.org/10.5194/essd-8-605-2016.

Li, W., Gao, K., 2012. A marine secondary producer respires and feeds more in a high CO2 ocean. Mar. Pollut. Bull. 64, 699-703.

Lischka, S., Stange, P., Riebesell, U., 2018. Response of pelagic calcifiers (Foraminifera, Thecosomata) to ocean acidification during oligotrophic and simulated up-welling conditions in the subtropical North Atlantic off gran canaria. Front. Mar. Sci. 5, 379.

Longhurst, A.R., Harrison, W.G., 1989. The biological pump: profiles of plankton production and consumption in the upper ocean. Prog. Oceanogr. 22, 47-123. https://doi.org/10. 1016/0079-6611(89)90010-4.

Longhurst, A., Sathyendranath, S., Platt, T., Caverhill, C., 1995. An estimate of global primary production in the ocean from satellite radiometer data. J. Plankton Res. 17, 1245-1271. https://doi.org/10.1093/plankt/17.6.1245.

Lowry, O.H., Rosebrough, N.J., Farr, A.L., Randall, R.J., 1951. Protein measurement with the folin phenol reagent. J. Biol. Chem. 193, 265-275.

Malzahn, A.M., Aberle, N., Clemmesen, C., Boersma, M., 2007. Nutrient limitation of primary producers affects planktivorous fish condition. Limnol. Oceanogr. 52, 2062-2071. https://doi.org/10.4319/lo.2007.52.5.2062.

Marrero-Betancort, N., Marcello, J., Rodríguez-Esparragón, D., Hernández-León, S., 2020. Wind variability in the canary current during the last 70 years. Ocean Sci. 16, 951-963. https://doi.org/10.5194/os-16-951-2020.

Mayzaud, P., Conover, R.J., 1988. O: N atomic ratio as a tool to describe zooplankton metabolism. Mar. Ecol. Prog. Ser. 45, 289-302.

Meunier, C.L., Algueró-Muñiz, M., Horn, H.G., Lange, J.A.F., Boersma, M., 2016. Direct and indirect effects of near-future pCO2 levels on zooplankton dynamics. Mar. Freshw. Res. 68, 373-380.

Nielsen, L.T., Jakobsen, H.H., Hansen, P.J., 2010. High resilience of two coastal plankton communities to twenty-first century seawater acidification: evidence from microcosm studies. Mar. Biol. Res. 6, 542-555. https://doi.org/10.1080/17451000903476941.

Omori, M., Ikeda, T., 1984. Ikeda Methods in Marine Zooplankton Ecology. John-Wiely and Sone. Inc, New York.

Orr, J.C., et al., 2005. Anthropogenic Ocean acidification over the twenty-first century and its impact on calcifying organisms. Nature 437, 681-686.

Osma, N., Maldonado, F., Fernández-Urruzola, I., Packard, T.T., Gómez, M., 2016a. Variability of respiration and pyridine nucleotides concentration in oceanic zooplankton. J. Plankton Res. 38, 537-550. https://doi.org/10.1093/plankt/fbw001.

Osma, N., Fernández-Urruzola, I., Gómez, M., Montesdeoca-Esponda, S., Packard, T.T., 2016b. Predicting in vivo oxygen consumption rate from ETS activity and bisubstrate enzyme kinetics in cultured marine zooplankton. Mar. Biol. 163, 146.
Osma, N., Aristizabal, M., Fernández-Urruzola, I., Packard, T.T., Gómez, M., 2016c. Influence of starvation on respiratory metabolism and pyridine nucleotide levels in the marine dinoflagellate Oxyrrhis marina. Protist 167, 136-147. https://doi.org/10.1016/j.protis. 2016.01.002

Owens, T., King, F.D., 1975. The measurement of respiratory electron transport system activity in marine zooplankton. Mar. Biol. 30, 27-36.

Packard, T.T., Williams, P.J.L., 1981. Rates of respiratory oxygen-consumption and electrontransport in surface seawater from the Northwest Atlantic. Oceanol. Acta 4, 351-358.

Packard, T.T., Healy, M.L., Richards, F.A., 1971. Vertical distribution of the activity of the respiratory electron transport system in marine plankton. Limnol. Oceanogr. 16, 60-70. https://doi.org/10.4319/1o.1971.16.1.0060.

Packard, T.T., et al., 1996. Oxygen consumption in the marine bacterium Pseudomonas nautica predicted from ETS activity and bisubstrate enzyme kinetics. J. Plankton Res. $18,1819-1835$.

Paul, A., et al., 2015. Effect of elevated CO2 on organic matter pools and fluxes in a summer Baltic Sea plankton community. Biogeosciences 12, 6181-6203.

Pedersen, S.A., et al., 2014. Multigenerational exposure to ocean acidification during food limitation reveals consequences for copepod scope for growth and vital rates. Environ. Sci. Technol. 48, 12275-12285.

Pierrot, D., Lewis, E., Wallace, D.W.R., 2006. CO2SYS DOS Program Developed for CO2 System Calculations. ORNL/CDIAC-105. Carbon Dioxide Information Analysis Center, Oak Ridge National Laboratory, US Department of Energy, Oak Ridge, Tennessee.

Riebesell, U., Gattuso, J.-P., 2015. Lessons learned from ocean acidification research. Nat. Clim. Chang. 5, 12-14.

Riebesell, U., et al., 2007. Enhanced biological carbon consumption in a high CO2 ocean. Nature $450,545-548$.

Riebesell, U., et al., 2013. Technical note: a mobile sea-going mesocosm system - new opportunities for ocean change research. Biogeosciences 10, 1835-1847. https://doi.org/10. 5194/bg-10-1835-2013.

Riebesell, U., et al., 2018. Toxic algal bloom induced by ocean acidification disrupts the pelagic food web. Nat. Clim. Chang. 8, 1082-1086.

Romero-Kutzner, V., et al., 2015. Respiration quotient variability: bacterial evidence. Mar. Ecol. Prog. Ser. 519, 47-59.

Rossoll, D., et al., 2012. Ocean acidification-induced food quality deterioration constrains trophic transfer. PLoS ONE 7, 1-6. https://doi.org/10.1371/journal.pone.0034737.

Rutter, W.J., 1967. Protein determinations in embryos. In: Wilt, F.H., Wessels, N.K. (Eds.), Methods in Developmental Biology, pp. 671-684 New York.

Saba, G.K., Schofield, O., Torres, J.J., Ombres, E.H., Steinberg, D.K., 2012. Increased feeding and nutrient excretion of adult Antarctic krill, Euphausia superba, exposed to enhanced carbon dioxide (CO2). PLOS ONE 7, e52224.

Sala, M.M., et al., 2015. Contrasting effects of ocean acidification on the microbial food web under different trophic conditions. ICES J. Mar. Sci. 73, 670-679. https://doi.org/10. 1093/icesjms/fsv130.

Sangrà, P., et al., 2009. The canary eddy corridor: a major pathway for long-lived eddies in the subtropical North Atlantic. Deep-Sea Res. I Oceanogr. Res. Pap. 56, 2100-2114. https:// doi.org/10.1016/j.dsr.2009.08.008.

Schmoker, C., Hernández-León, S., 2013. Stratification effects on the plankton of the subtropical canary current. Progr. Oceanogr. 119, 24-31. https://doi.org/10.1016/j.pocean. 2013.08.006.

Sieburth, J.M., Smetacek, V., Lenz, J., 1978. Pelagic ecosystem structure: heterotrophic compartments of the plankton and their relationship to plankton size fractions. Limnol. Oceanogr. 23, 1256-1263.

Solorzano, L., 1969. Determination of ammonia in natural waters by the phenolhypochlorite method. Limnol. Oceanogr. 14, 799-801.

Stange, P., et al., 2018. Ocean acidification-induced restructuring of the plankton food web can influence the degradation of sinking particles. Front. Mar. Sci. 5, 1-13.

Steinberg, D.K., Landry, M.R., 2017. Zooplankton and the ocean carbon cycle. Annu. Rev. Mar. Sci. 9, 413-444. https://doi.org/10.1146/annurev-marine-010814-015924.

Tames-Espinosa, M., et al., 2020. Metabolic responses of subtropical microplankton after a simulated deep-water upwelling event suggest a possible dominance of mixotrophy under increasing CO2 levels. Front. Mar. Sci. 7 61-15.

Taucher, J., et al., 2017. Influence of ocean acidification and deep water upwelling on oligotrophic plankton communities in the subtropical North Atlantic: insights from an in situ mesocosm study. Front. Mar. Sci. 4, 85.

Taucher, J., et al., 2018. Response of subtropical phytoplankton communities to ocean acidification under oligotrophic conditions and during nutrient fertilization. Front. Mar. Sci. 5, 330

Taucher, J., et al., 2020. Changing carbon-to-nitrogen ratios of organic-matter export under ocean acidification. Nat. Clim. Chang. 1-14.

Todgham, A.E., Hofmann, G.E., 2009. Transcriptomic response of sea urchin larvae Strongylocentrotus purpuratus to CO2-driven seawater acidification. J. Exp. Biol. 212, 2579-2594.

Utermöhl, H., 1958. Methods of collecting plankton for various purposes are discussed. SIL Commun. 1953-1996 (9), 1-38. https://doi.org/10.1080/05384680.1958.11904091.

Vargas, C.A., et al., 2017. Species-specific responses to ocean acidification should account for local adaptation and adaptive plasticity. Nat. Ecol.Evol. 1, 0084. https://doi.org/10 1038/s41559-017-0084.

Waldbusser, G.G., Salisbury, J.E., 2014. Ocean acidification in the coastal zone from an organism's perspective: multiple system parameters, frequency domains, and habitats. Annu. Rev. Mar. Sci. 6, 221-247. https://doi.org/10.1146/annurev-marine-121211-172238.

Wang, M., Jeong, C.-B., Lee, Y.H., Lee, J.-S., 2018. Effects of ocean acidification on copepods. Aquatic Toxicol. 196, 17-24. https://doi.org/10.1016/j.aquatox.2018.01.004.

Wittmann, A.C., Pörtner, H.-O., 2013. Sensitivities of extant animal taxa to ocean acidification. Nat. Clim. Chang. 3, 995-1001. 